Research Article

\title{
The Piston Ring-Cylinder Bore Interface Leakage of Bent-Axis Piston Pumps Based on Elastohydrodynamic Lubrication and Rotation Speed
}

\author{
Lvjun Qing $\mathbb{D}^{1,2}$ Lichen Gu, ${ }^{1,3}$ Yan Wang, ${ }^{1}$ Wei Xue, ${ }^{4}$ and Zhufeng Lei ${ }^{2}$ \\ ${ }^{1}$ National Engineering Laboratory for Highway Maintenance Equipment, Chang'an University, Xi'an 710064, China \\ ${ }^{2}$ National Joint Engineering Research Center for Special Pump Technology, Xi'an Aeronautical University, Xi'an 710077, China \\ ${ }^{3}$ Institute of Electromechanical Technology, Xi'an University of Architecture and Technology, Xi'an 710055, China \\ ${ }^{4}$ Institute of Geology of the Fifth Oil Production Plant, PetroChina Changqing Oilfield Company, Xi'an 710000, China
}

Correspondence should be addressed to Lichen Gu; gulichen@126.com

Received 19 January 2021; Revised 12 February 2021; Accepted 16 February 2021; Published 22 February 2021

Academic Editor: Ke Feng

Copyright (C) 2021 Lvjun Qing et al. This is an open access article distributed under the Creative Commons Attribution License, which permits unrestricted use, distribution, and reproduction in any medium, provided the original work is properly cited.

The bent-axis piston pump is the core component of electrohydrostatic actuators (EHA) in aerospace applications, and its wear of key friction interfaces is greatly related to the healthy operation of pumps. The leakage of the piston ring-cylinder bore interface (PRCB), as the important part of the return oil flow of the pump house that commonly assesses the wear of key friction interfaces in piston pumps, is changed with the rotation speed. Thus, the wear of key friction interfaces is usually inaccurate by using the leakage of PRCB. In order to obtain the relationship between the PRCB leakage and the rotation speed, an elastohydrodynamic lubrication model is proposed. First, the proposed model includes a minimum film thickness model of PRCB to analyze the dynamic change of oil film of PRCB when subject to the elastohydrodynamic lubrication. After that, a mathematical model of PRCB is induced by combining the minimum film thickness model with the flow equation, which helps produce the effects of the oil film on the leakage of PRCB. The proposed model is verified by numerical simulation and experiment. The results show that the leakage of PRCB has a negative effect on the return oil flow of the pump case in the range of rotation speed of $700-1300 \mathrm{r} / \mathrm{min}$ and discharge pressure of 10-20 MPa. Furthermore, the leakage of PRCB is proportional to the rotation speed, but the return oil flow of the pump case is decreased. The effects of rotation speed are enhanced under the high discharge pressure conditions.

\section{Introduction}

Bent-axis piston pumps are widely used in electrohydrostatic actuators (EHA) in aerospace applications due to the advantage of miniaturization and lightweight through high speed and high pressure. Therefore, the bent-axis piston pump greatly affects the healthy operation of EHA [1-3].

Performance degradation prediction and fault diagnosis are of great significance to ensure the safe and stable operation of mechanical equipment and reduce maintenance cost $[4,5]$. In hydraulic pumps, the wear of key friction pairs is a major cause of the degradation of hydraulic pump performance [6-9]. As the wear increases with pump working time, the lubricating interface gap increases and the lubricating interface leakage increases, which eventually leads to the increase of the return oil flow rate of the pump case $[10,11]$. Hence, the return oil flow rate is often used to evaluate the wear state of the key friction pairs in the piston pump [12-14]. In engineering scenarios, however, the lubricating interface leakage is inevitably changed with the varying working conditions, such as the rotation speed, which affects the accurate evaluation of wear states.

The bent-axis piston pump is shown in Figure 1. The cylinder block moves synchronously with the drive shaft through the bevel gears, and the piston reciprocates in the cylinder bore. The piston ring with the spherical crosssection is usually installed on the end of the piston to reduce the leakage between the piston and the cylinder bore. There are two lubricating interfaces, that is, the valve plate-cylinder block interface (VPCB) and the piston ring-cylinder bore 
interface (PRCB). As one of the two lubricating interface leakages, PRCB leakage directly affects the return oil flow rate in bent-axis piston pump.

The lubrication interface gap, as the main parameter affecting PRCB leakage, is influenced by multifactor interactions. Pelosi et al. developed the fully coupled multibody dynamics model to capture the complex fluid-structure interaction phenomena affecting the nonisothermal fluid film conditions and analyzed the influence of the squeeze film effect and elastic deformation on the piston-cylinder interface [15]. In order to improve energy efficiency of piston pump, Song et al. presented a numerical method to analyze influence of temperature on lubricant film characteristics of the piston-cylinder interface [16]. Qian et al. presented a nonisothermal fluid-structure mathematical model considering the piston eccentricity, elastic deformations, and the fluid physical properties to analyze the piston-cylinder bore interface leakage and the fluid pressure distribution [17]. Zhang et al. established the mathematical model of the oil film thickness by using the cosine theorem in the cross section of the piston and studied the piston-cylinder interface leakage and pressure field under the condition of ultrahigh pressure [18]. Nie et al. established a parameterized elastohydrodynamic lubrication model and studied the influence of the elastohydrodynamic behavior, viscosity temperature effect, and deep-sea environmental pressure on piston-cylinder interface leakage in seawater hydraulic axial piston pump [19]. Cho et al. analyzed the film thickness, the pressure distribution, and the friction force of piston ringcylinder bore interface under elastic deformation of plunger ring in bent-axis piston pump with the tapered piston [20]. Kumar established the theoretical model of the piston ringpiston bore pair in the bent-axis piston pump with rectangular cross-section of piston ring and analyzed the leakage flow characteristics between piston ring and cylinder bore under different working conditions through numerical simulation and test [21]. Manhartsgruber analyzed the dynamics of the leakage of the bent-axis piston pump with the tapered piston and revealed the influence of the piston rotation inside the cylinder bore on the pressure fluctuation under low speed and low pressure condition by experiment [22]. Zhang et al. analyzed the effect of centrifugal force and reciprocation inertial force on the leakage between piston and cylinder in the bent-axis piston pump under high speed and show the leakage of piston-cylinder pair increases obviously at high speed [23].

From the literature review, the previous studies mentioned mainly focused on the influence of the piston eccentricity, elastic deformation, and thermal effect on the piston-cylinder bore interface leakage in the swash-plate piston pump. Some researchers studied the effects of the elastic deformation and micromotion of piston ring on the oil film thickness, pressure field, and friction force of PRCB in the bent-axis piston pump under certain rotation speed conditions. However, the variable speed and wide speed are the typical working conditions of bent-axis piston pump in EHA, and the influence of rotation speed on PRCB leakage considering elastohydrodynamic lubrication effect has not been fully elucidated.
Rotation speed and its fluctuation are very meaningful monitoring parameters, and the leakage analysis of the friction pairs is also related to the rotation speed. Our previous research has proved that the operating state information of the swash-plate piston machine can be extracted from the speed fluctuation signal [24-27]. In this study, an elastohydrodynamic lubrication model is proposed to discuss the influence of rotation speed on the leakage of PRCB. The proposed model includes a minimum oil film model of PRCB to analyze the dynamic change of minimum oil film of PRCB under the elastohydrodynamic lubrication. Combining the minimum oil film model with the flow equation, a mathematical model of PRCB is induced to help produce the effects of the oil film on the leakage of PRCB. The accuracy of the proposed model is verified by simulation and experiment, which provides guidance on the piston pump wear diagnosis based on the leakage. The layout of this paper is organized as follows. A theoretical model of PRBC is established and explained in detail in Section 2. The simulation results are discussed in Section 3. The experimental results are presented in Section 4, followed by the conclusions in Section 5.

\section{Elastic Deformation and Leakage Mechanism of PRBC}

2.1. Elastohydrodynamic Lubrication Equations. In order to reduce the leakage of $\mathrm{PRCB}$, a ring groove is usually opened on the spherical surface of the large end of the piston, and a piston ring is installed in the ring groove. The boundary conditions between the piston ring and the cylinder bore are different because of the change of the angle position of the piston in the suction and discharge region, as shown in Figure 2.

Because of the elastic deformation of the contact surface in the piston ring at relative motion, the gap of PRCB is changed, which affects the leakage. Therefore, it is necessary to access elastohydrodynamic lubrication (EHL) to analyze the leakage between the piston ring and the cylinder bore. The analysis model between the piston ring and the cylinder bore is shown in Figure 3. $V$ represents the sliding velocity of the piston and the piston ring relative to the cylinder bore, $R$ is the radius of the piston ring section, $W$ is the unit load on the piston ring. Figures 3(a) and 3(b) show the pressure distribution of lubricating oil film between the piston ring and the cylinder bore, and its typical characteristics are the primary peak pressure and the secondary peak pressure. $P_{1}$ represents the initial pressure of the oil film, and it equals the pressure in the displacement chamber, and $P_{2}$ represents the pressure at the end of the film, and it equals the pressure in the pump case.

The assumptions for the EHL analysis between the piston ring and the cylinder bore are listed as follows:

(1) The lubricating pressure remains unchanged along the direction of film thickness

(2) The lubricating oil film remains unchanged along the circumferential direction of piston bore

(3) The fluid inertia force is ignored 


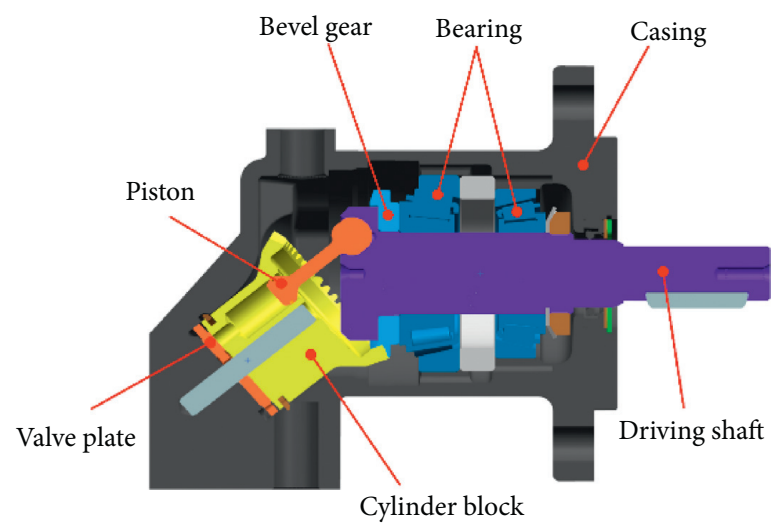

FIgURE 1: The configuration of a bent-axis piston pump.

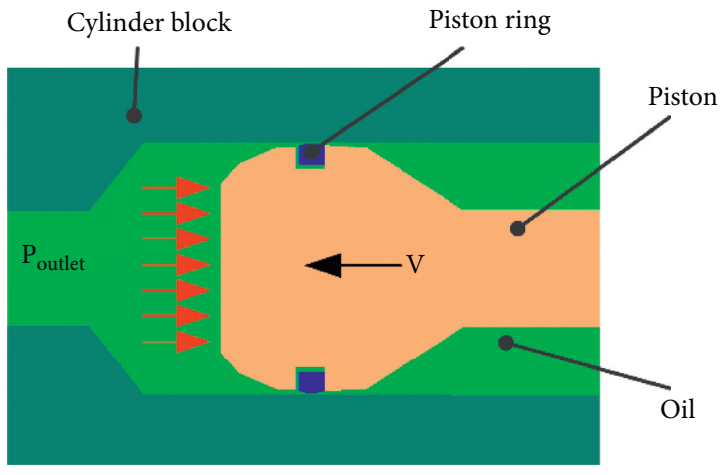

(a)

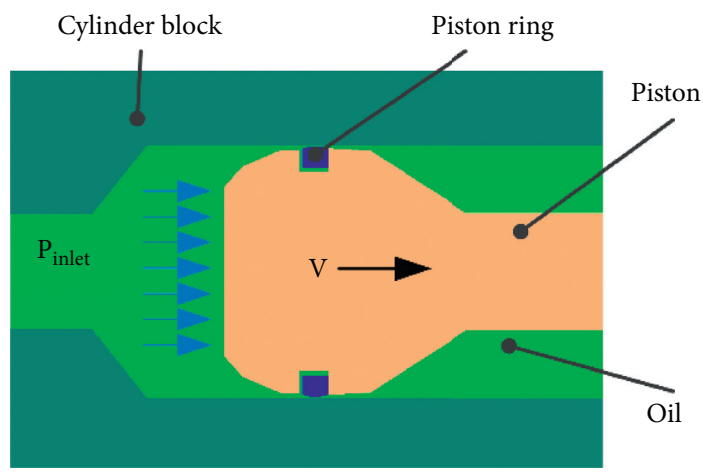

(b)

Figure 2: The behavior of PRCB. (a) The discharge region; (b) the suction region.

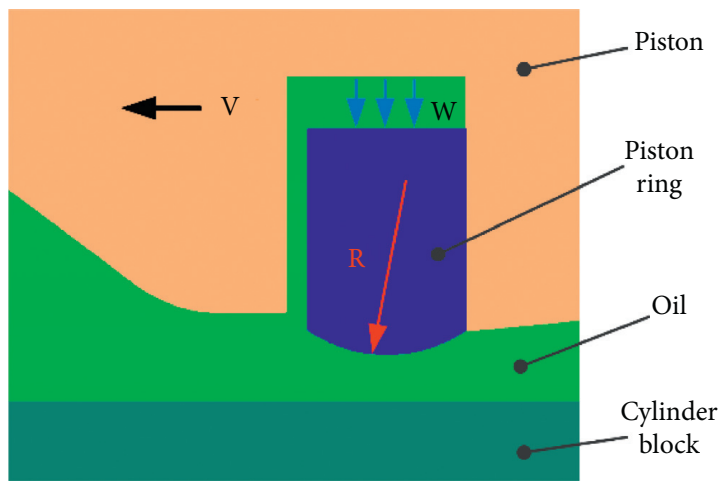

(a)

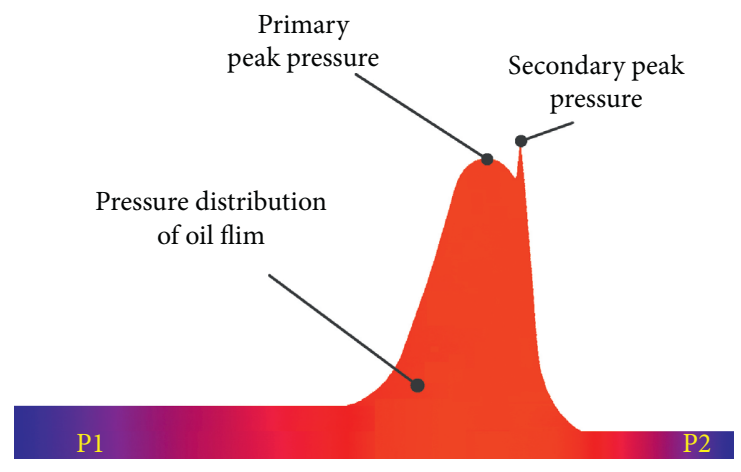

(b)

Figure 3: The analysis model of PRCB. (a) The configuration of PRCB; (b) the pressure distribution of PRCB.

(4) The compressibility and viscosity temperature characteristics of the lubricating oil film are ignored

(5) The only concern is the velocity gradient along the piston ring direction of motion

The Reynolds equation for one-dimensional isothermal elastohydrodynamic lubrication is shown as follows [28]:

$$
\frac{d}{d x}\left(\frac{\rho h^{3}}{\eta} \frac{d p}{d x}\right)=12 u_{s} \frac{d(\rho h)}{d x},
$$

where $\rho$ is oil film density, $h$ is the oil film thickness, $p$ is the pressure distribution of lubricating oil film, $p=p_{1}$ at $x=x_{a}$, $p=p_{2}, \partial p / \partial x=0$ at $x=x_{b}, u_{s}$ is the average oil film velocity, $u_{s}=v / 2$, and $\eta$ is the viscosity oil film. 
The velocity of the piston relative to the cylinder bore can be expressed as follows:

$$
v=-R_{0} \omega \sin \gamma \sin \varphi,
$$

where $R_{0}$ is the nominal pitch circle radius of piston balls on the driving flange, $\omega$ is the angular velocity of the driving shaft, $\varphi$ is the angular position of piston relative to the top dead point, $\gamma$ is the angle between the axis of the cylinder and axis of the driving shaft.

The film thickness is expressed as follows [29]:

$$
h(x)=h_{0}+\frac{x^{2}}{2 R}-\frac{2}{\pi E^{\prime}} \int_{x_{0}}^{x_{e}} p(s) \ln (s-x)^{2} d s+C,
$$

where $1 / E^{\prime}=1 / 2\left(1-\mu_{1}^{2} / E_{1}+1-\mu_{2}^{2} / E_{2}\right), \quad \mu_{1}, \quad E^{\prime}$ is the equivalent Young's modulus, $\mu_{1}$ and $\mu_{2}$ are Poisson's ratio of the piston ring and the cylinder, $E_{1}$ and $E_{2}$ are Young's modulus of the piston ring and the cylinder, $h_{0}$ is the film thickness at $x=0$, and $C$ is the integral calculus constant.

The viscosity coefficient and density coefficient of lubricating oil are expressed as follows [30]:

$$
\eta=\eta_{0} \exp \left\{\left(\ln \eta_{0}+9.67\right)\left[-1+\left(\frac{1+p}{p_{0}}\right)^{z}\right]\right\} \text {. }
$$

The density coefficient of lubricating oil is expressed as follows [31]:

$$
\rho=\rho_{0}\left(1+\frac{0.6 p}{1+1.7 p}\right)
$$

where $\eta_{0}$ is the viscosity of oil under atmospheric pressure, $p_{0}$ and $z$ are the pressure-viscosity coefficients, and $\rho_{0}$ is the density of oil under atmospheric pressure.

The unit load on piston ring is expressed as follows:

$$
\omega-\int_{x_{a}}^{x_{b}} p(x) d x=0,
$$

where $x_{a}$ is the starting point of lubricating film in the analysis and $x_{b}$ is the ending point.

2.2. PRCB Leakage Model. The PRCB leakage is composed of two parts. One is the Poiseuille flow by the pressure difference between the displacement chamber and the pump case, and the other is the Couette flow by the piston ring relative to the cylinder bore motion and the hydraulic oil viscosity. As the most important parameter of PRCB, the minimum oil film varies dynamically with the piston velocity due to the elastohydrodynamic lubrication effect, which will change the proportion of the Poiseuille flow and the Couette flow in the gap and then affect the leakage flow of PRCB. The dynamic model of the leakage flow of PRCB is established by combining the minimum oil film of PRCB with the flow equation, which is the theoretical basis for the subsequent study of the leakage flow of the plunger pair under the variable speed condition.

The instantaneous leakage flow rate between the piston ring and the cylinder bore is expressed as follows [23]:

$$
q_{l p i}=\frac{\pi d_{c} \delta_{p}^{3}\left(1+1.5 \varepsilon^{2}\right)}{12 \mu l_{i}} \Delta p-\frac{\pi d_{c} \delta_{p}}{2} v
$$

where $d_{c}$ is the diameter of piston, $\delta_{p}$ is the gap between piston ring and cylinder bore, $\Delta p$ is the pressure difference between displacement chamber and pump case, $\mu$ is the oil viscosity, $l_{i}$ is the width of piston ring, $\varepsilon$ is the eccentricity of the piston ring, and $v$ is the velocity of motion of piston ring in the cylinder bore.

The average leakage flow rate of PRCB is expressed as

$\bar{q}_{l p i}=\frac{N}{T_{0}} \int_{0}^{T_{0}} \frac{\pi d_{c} \delta_{p}^{3}\left(1+1.5 \varepsilon^{2}\right)}{12 \mu l_{i}} \Delta p d t-\frac{N}{T_{0}} \int_{0}^{T_{0}} \frac{\pi d_{c} \delta_{p} v_{p i}}{2} d t$,

where $N$ is number of the pistons and $T_{0}$ is the time during one rotating speed of the bent-axis piston pump.

\section{Simulation Results}

3.1. Simulation Parameter Setting. The finite difference method is used to solve the theoretical model. In order to improve the calculation accuracy, the central difference scheme is used to discretize the Reynolds equation. The flow chart of the numerical calculation program for the elastohydrodynamic lubrication problem of PRCB is shown in Figure 4.

According to the given working parameters and the initial values of oil film thickness, distribution pressure, viscosity, density and other parameters, the Reynolds equation is calculated to obtain the new oil film distribution pressure, and then the elastic deformation, viscosity, density, and other parameters of the piston ring are calculated under the obtained pressure.

The Gauss-Seidel iterative method is used to solve the algebraic equations of Reynolds equation discretization, and the converging condition is expressed as follows:

$$
p_{i}^{k+1}=(1-\alpha) p_{i}^{k}+\alpha \bar{p}_{i}^{k},
$$

where $\alpha$ is the relaxation factor and $\alpha=0.8$ is chosen to obtain a fast convergence, $p_{i}^{k}$ and $p_{i}^{k+1}$ are the pressure values at steps $k$ and $k+1$, and $\bar{p}_{i}^{k}$ is the temporary value at step $k+1$.

The whole process is repeated until the error tolerance of the Reynolds equation at each node is less than the relative precision requirement $\varepsilon=1 \times 10^{-5}$; the error tolerance of the Reynolds equation $\varepsilon$ is expressed as follows:

$$
\left|\frac{p_{i}^{k+1}-p_{i}^{k}}{p_{i}^{k+1}}\right| \leq \varepsilon
$$

MATLAB platform is used to calculate the leakage flow rate between piston ring and cylinder bore. In order to compare the characteristics of the leakage with different operating conditions, the parameters of simulation calculation process are set in Table 1. 


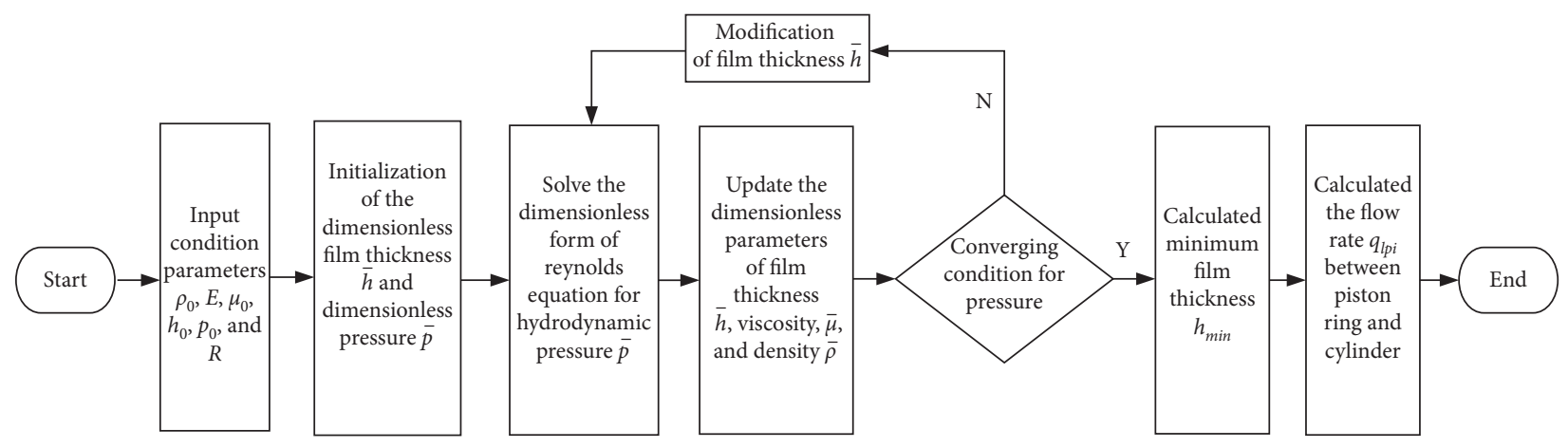

FIgURE 4: Flow chart of the calculation process.

TABLE 1: Simulation parameters setting.

\begin{tabular}{lcc}
\hline Description & Numerical value & Unit \\
\hline Suction pressure & 0.1 & $\mathrm{MPa}$ \\
Discharge pressure & $10,15,20$ & $\mathrm{MPa}$ \\
Rotation speed & $700,800,900,1000,1100,1200,1300$ & $\mathrm{r} / \mathrm{min}$ \\
Oil viscosity (at $\left.40^{\circ} \mathrm{C}\right)$ & 0.046 & $\mathrm{Pa.s}$ \\
Diameter of distribution circle in piston head & 68.1 & $\mathrm{~mm}$ \\
Diameter of cylinder bore & 16 & $\mathrm{~mm}$ \\
Number of pistons & 7 & deg \\
Swivel angle & 40 & $\mathrm{~mm}$ \\
Width of piston ring & 3.2 & \\
\hline
\end{tabular}

\subsection{Analysis of Simulation Results}

3.2.1. The Pressure Distribution of $P R C B$. The pressure distribution of PRCB in the discharge region is shown in Figure 5.

As shown in Figure 5, the pressure of oil film changes in the lubrication zone at a certain angle position, and there is the maximum pressure value (the local maximum pressure). The local maximum pressure varies with the angular position of the discharge region, and there is also the maximum pressure (the global maximum pressure). As a whole, the local maximum pressure in the discharge region decreases first and then increases with the increase of angle position, and the global maximum pressure is $146 \mathrm{MPa}$ at angle position $\varphi=4.7^{\circ}$, while the angle position is near the top dead point $0^{\circ}$ and the bottom dead point $180^{\circ}$; the local maximum pressure changes dynamically again. The reason is that the piston velocity is small near the top and bottom dead points, and the local maximum pressure is determined by the primary peak pressure, as shown in Figure 3(b). However, the local maximum pressure is determined by the secondary peak pressure in other region, and the secondary peak pressure decreases with the increase of the piston velocity.

The local maximum pressure distribution of PRBC in the discharge region at different speeds is shown in Figure 6.

As shown in Figure 6, when the speed increases from $700 \mathrm{r} / \mathrm{min}$ to $1300 \mathrm{r} / \mathrm{min}$ with a step of $200 \mathrm{r} / \mathrm{min}$, the global maximum pressure is basically not affected by the change of speed, which is kept at $146 \mathrm{MPa}$, but the angular position of the global maximum pressure decreases from $4.7^{\circ}$ to $2.5^{\circ}$.

The local maximum pressure distribution of PRBC in the discharge region at different discharge pressure is indicated in Figure 7.
As indicated in Figure 7, when the discharge pressure increases from $10 \mathrm{MPa}$ to $20 \mathrm{MPa}$ at $n=700 \mathrm{r} / \mathrm{min}$, the local maximum pressure becomes larger as a whole, the global maximum pressure increases from $146 \mathrm{MPa}$ to $205 \mathrm{MPa}$, and the angular position of the global maximum pressure increases from $4.7^{\circ}$ to $15.3^{\circ}$.

The rotation speed has a weak effect on the value of the global maximum pressure, which has a significant effect on its the angular position. The discharge pressure has important influence on the value and the angle position of the global maximum pressure. The reason is that the global maximum pressure of PRBC in the discharge area is determined by the secondary peak pressure of the lubricating oil film. The secondary peak pressure is positively correlated with the discharge pressure. The angle position of the secondary peak pressure is affected by the rotation speed and the discharge pressure. The angular position of the secondary peak is positively correlated with the discharge pressure, and it is negatively correlated with the rotation speed.

3.2.2. The Minimum Thickness of PRCB. The minimum thickness of PRCB at different speed is displayed in Figure 8.

As displayed in Figure 8, the minimum film thickness increases first and then decreases with the increase of angle position in the discharge region and the suction region. However, the minimum film thickness of PRCB in the discharge region is obviously larger than that in the suction region as a whole. When the speed increases from $700 \mathrm{r} / \mathrm{min}$ to $1300 \mathrm{r} / \mathrm{min}$ with a step of $100 \mathrm{r} / \mathrm{min}$, the minimum thickness increases in the discharge region and the suction region, and its increase in the discharge region is greater. 


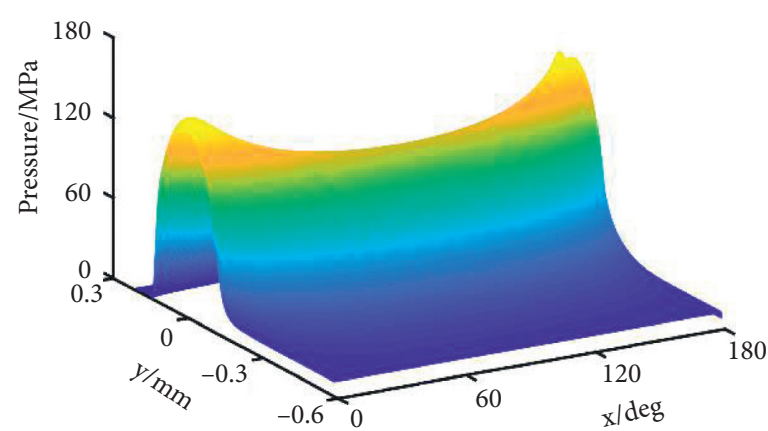

(a)

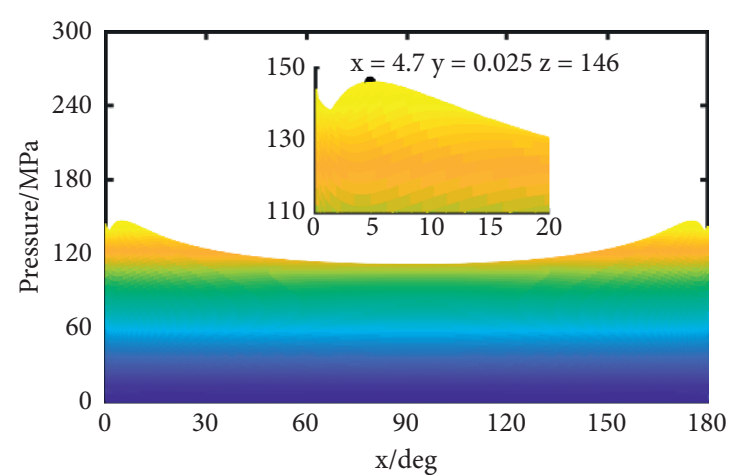

(b)

Figure 5: The pressure distribution of PRCB at $n=700 \mathrm{r} / \mathrm{min} p=10 \mathrm{MPa}$. (a) 3D diagram of oil film pressure distribution. (b) Right view of oil film pressure distribution.

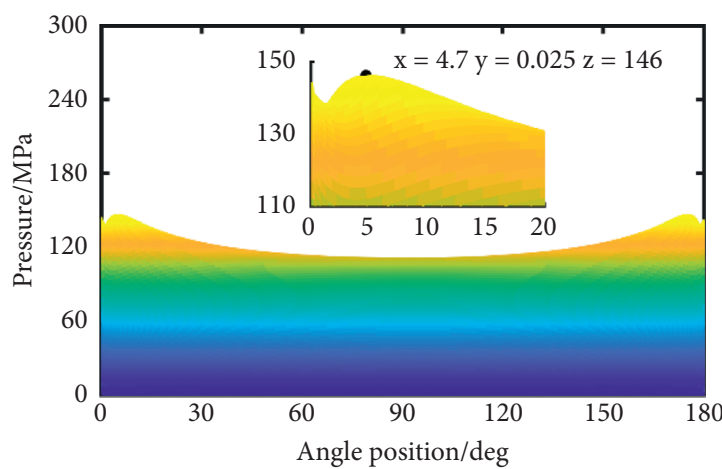

(a)

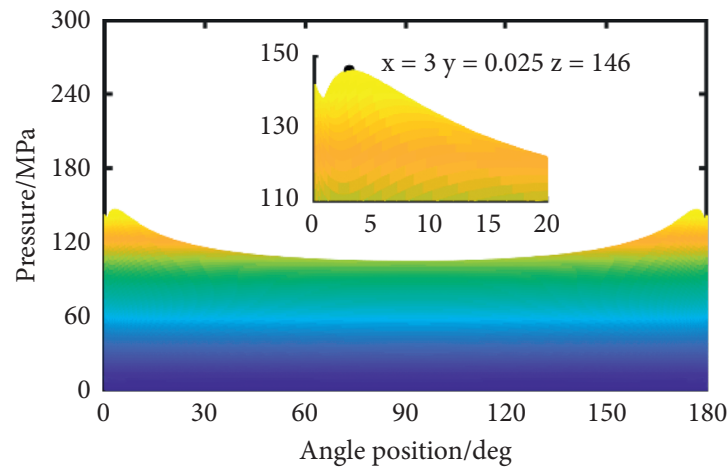

(c)

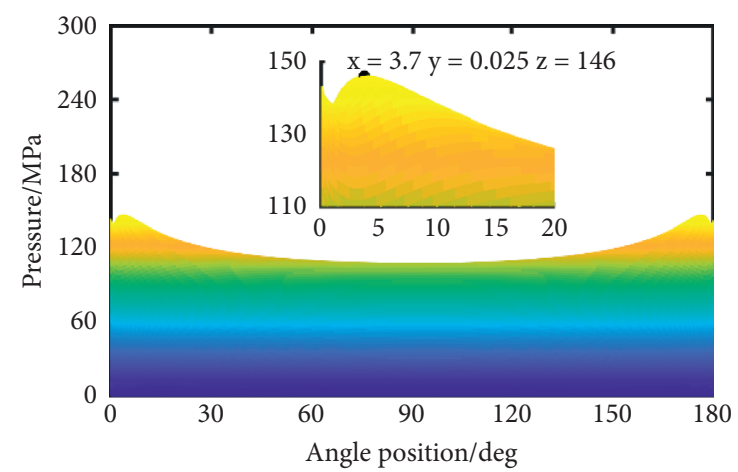

(b)

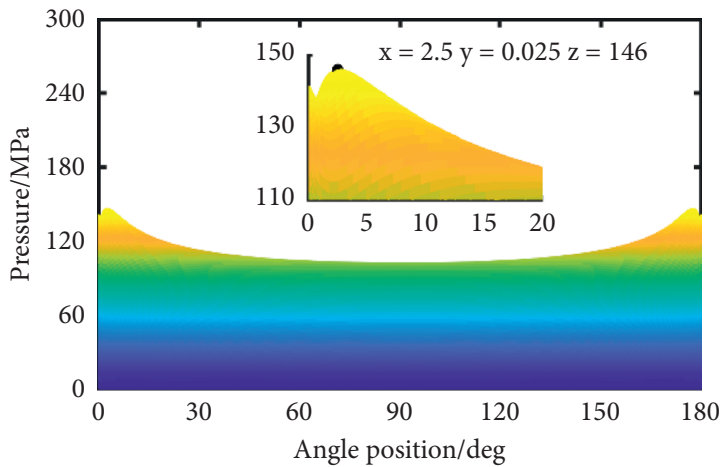

(d)

Figure 6: The effect of speed on the local maximum pressure distribution of the oil film at $p=10 \mathrm{MPa}$. (a) $n=700 \mathrm{r} / \mathrm{min}$; (b) $n=900 \mathrm{r} / \mathrm{min}$; (c) $n=1100 \mathrm{r} / \mathrm{min}$; (d) $n=1300 \mathrm{r} / \mathrm{min}$.

The effect of discharge pressure on the minimum thickness of PRCB is shown in Figure 9.

As shown in Figure 9, the minimum thickness of PRBC in the discharge region and the suction region increases first and then decreases with the increase of angular position, but the former is larger than the latter as a whole. When the discharge pressure increases gradually from $10 \mathrm{MPa}$ to $20 \mathrm{MPa}$ with a step of $5 \mathrm{MPa}$, the minimum oil film increases obviously in the oil drainage region, but only slightly in the suction region.
The reason is that the minimum thickness is determined by the velocity and the load of the piston ring. When the rotation speed and the discharge pressure are constant, the velocity of piston ring increases first and then decreases from the top dead point (TDC) to the bottom dead point (BDC) in the drainage region and is the same change trend from BDC to TDC in the suction region, so the change law of minimum thickness is the same as the velocity of piston ring. The discharge pressure mainly affects the load of the piston ring in the discharge region, and the discharge pressure increases, 


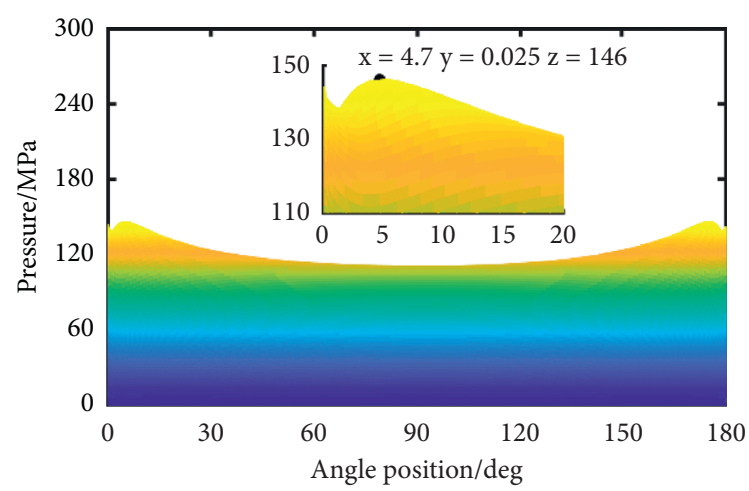

(a)

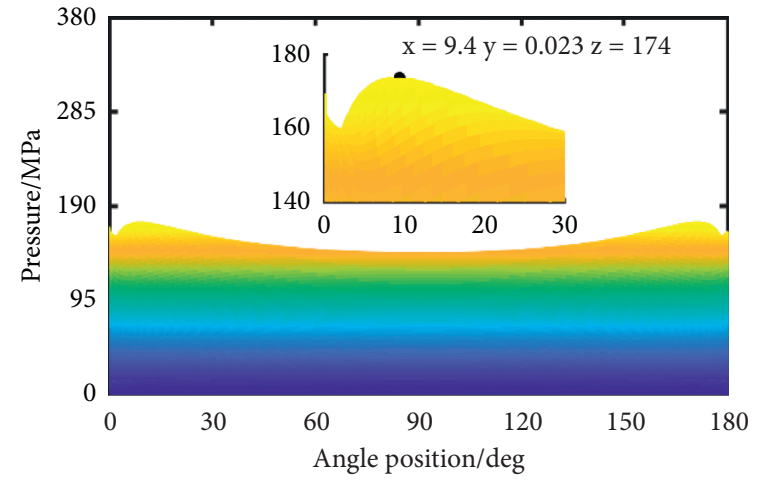

(b)

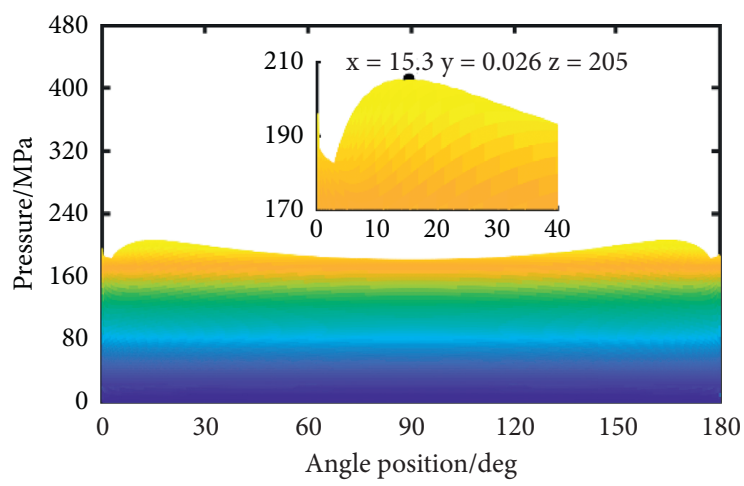

(c)

Figure 7: The effect of discharge pressure on the local maximum pressure distribution at $n=700 \mathrm{r} / \mathrm{min}$. (a) $p=10 \mathrm{MPa}$; (b) $p=15 \mathrm{MPa}$; (c) $p=20 \mathrm{MPa}$.
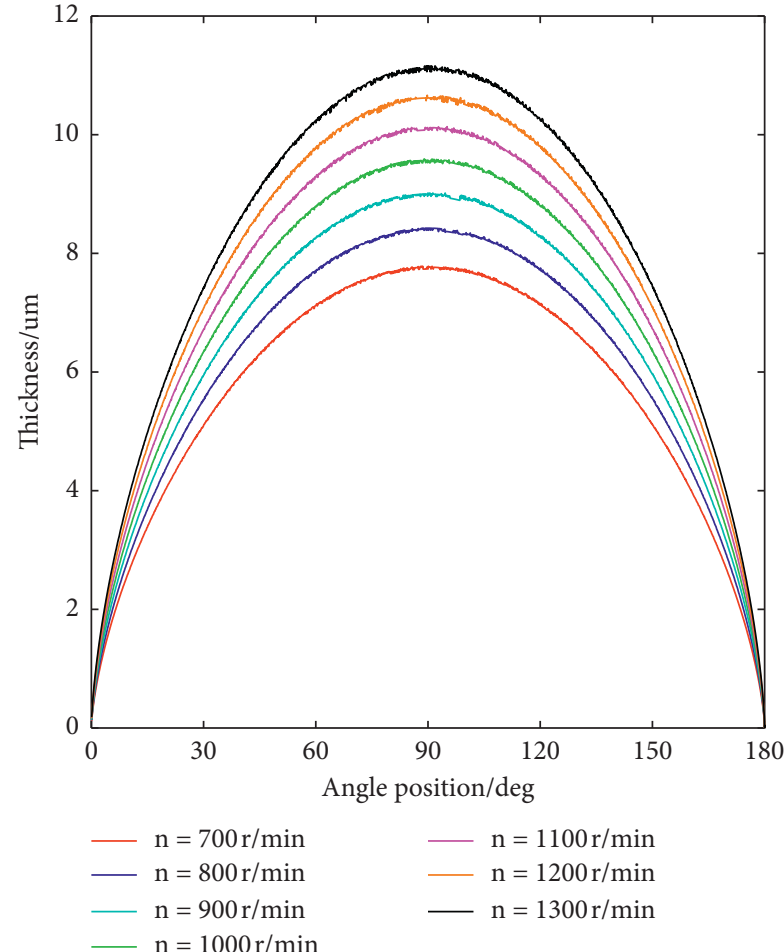

(a)
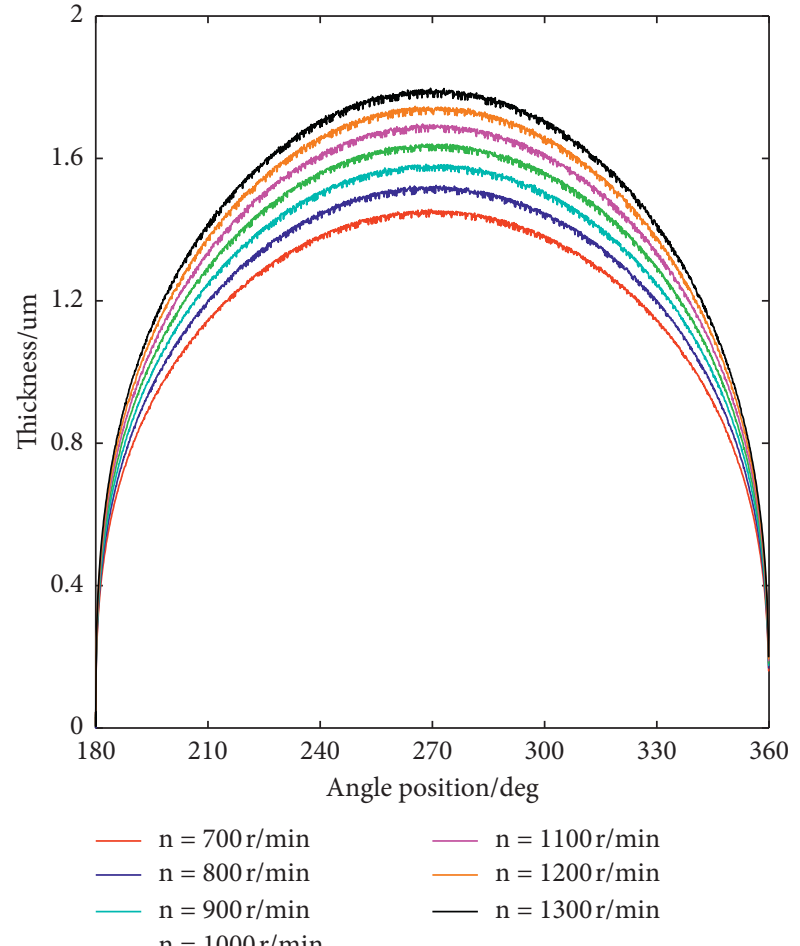

(b)

FIgURE 8: The minimum thickness of PRCB at different speeds. (a) The discharge region; (b) the suction region. 


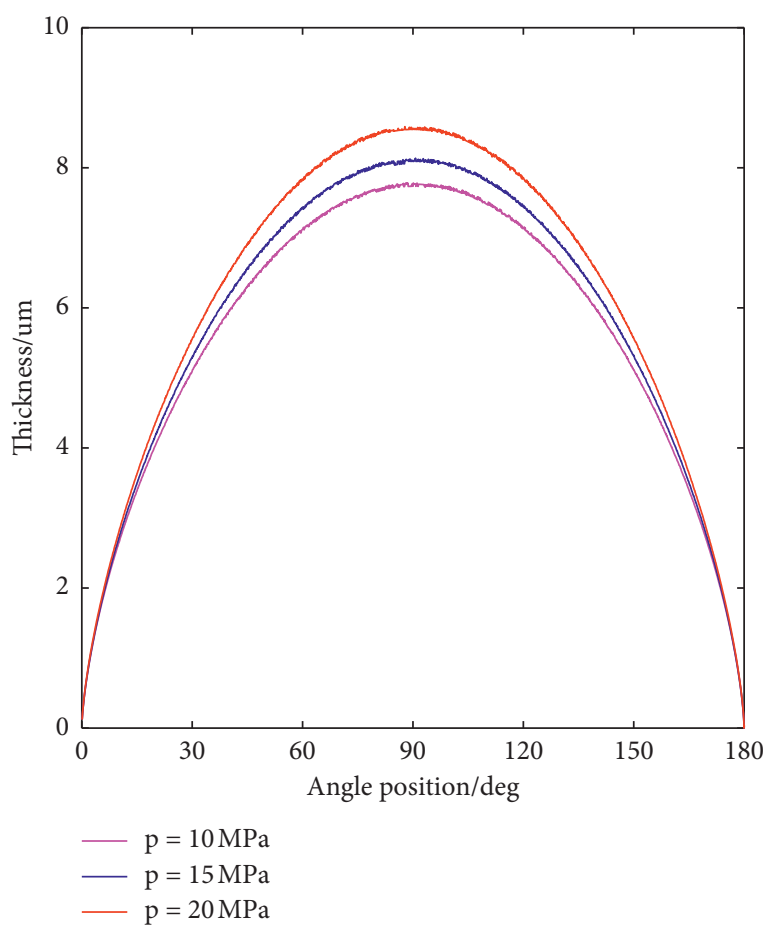

(a)

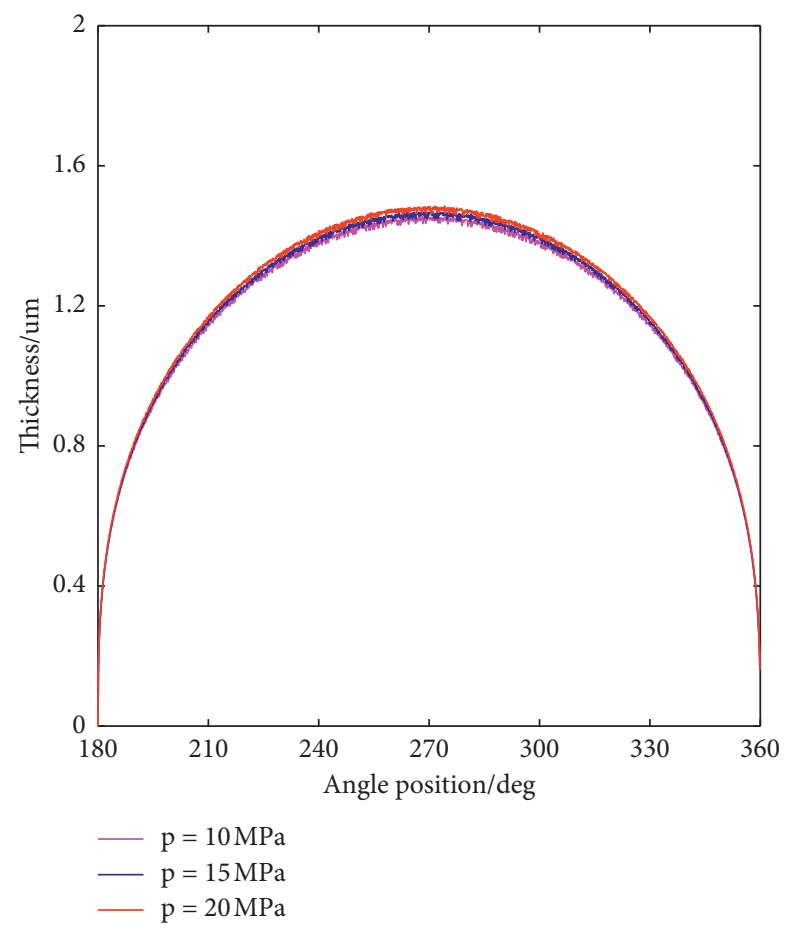

(b)

Figure 9: The minimum thickness at different pressure. (a) The discharge region; (b) the suction region.

and the load of the piston ring becomes larger, which leads to the increase of the elastic deformation of the piston ring, so the minimum thickness in the discharge region is greater than that in the suction region.

The mean value of minimum thickness of PRCB is shown in Figure 10.

As shown in Figure 10, it is found that the mean value of the minimum thickness in the discharge region and the suction region increases with the increasing rotation speed. When the discharge pressure is $20 \mathrm{MPa}$, with the rotation speed increasing from $700 \mathrm{r} / \mathrm{min}$ to $1300 \mathrm{r} / \mathrm{min}$, the mean value of the minimum thickness changes the most, and the variation in the mean value in the discharge region is 2.87 um, while the variation in the mean value in the suction region is $0.28 \mathrm{um}$.

The speed has obvious influence on the mean value of minimum thickness in the discharge region and the suction region, and the mean increases with the increase of the speed. The discharge pressure has obvious influence on the mean in the discharge area, and the mean value increases with the increase of discharge pressure, but the discharge pressure has a weak effect on the mean in the suction area. The mean of minimum thickness in the discharge area is obviously higher than that in the suction area.

As the speed increases from $700 \mathrm{r} / \mathrm{min}$, the variation of the mean minimum thickness increases with the increase of the variation of the speed in the discharge region and suction region, especially high discharge pressure, as described in Figure 11.

In this picture, the variation of mean minimum thickness in the discharge region is greater. Moreover, the variation in the discharge region is obviously higher than that in the suction region. The maximum of variation in the discharge region is $2.87 \mathrm{um}$, and the maximum of variation in the suction region is $0.28 \mathrm{um}$, and the former is 10 times the latter at $p=20 \mathrm{MPa}$.

3.2.3. The Leakage Flow Rate of PRCB per Piston. The leakage of PRCB is caused by the Poiseuille flow and the Couette flow. The leakage from the displacement chamber to the pump case is positive, whereas the leakage is negative. When the piston is in the suction region, the Poiseuille flow is not considered because the pressure difference between the displacement chamber and the pump case is very small.

The effect of rotation speed on the instantaneous flow of PRCB per piston is presented in Figure 12.

As presented in Figure 12, the Poiseuille flow first increases and then decreases with the increase of angular position in the discharge region, and the Poiseuille flow in the discharge pressure increases with the increase of speed, as shown in Figure 12(a). The Couette flow is negative in the discharge pressure region and is positive in the suction region. The value of the Couette flow first increases and then decreases with the increase of angular position, but the value of the Couette flow in the discharge region is significantly larger. When the speed increases from $700 \mathrm{r} / \mathrm{min}$ to $1300 \mathrm{r} /$ min, the leakage flow in the discharge region and suction region increases, but the variation of the former is larger, as shown in Figure 12(b). The total flow rate of PRCB is negative in the discharge area and positive in the suction area. The value of the total leakage increases with the 

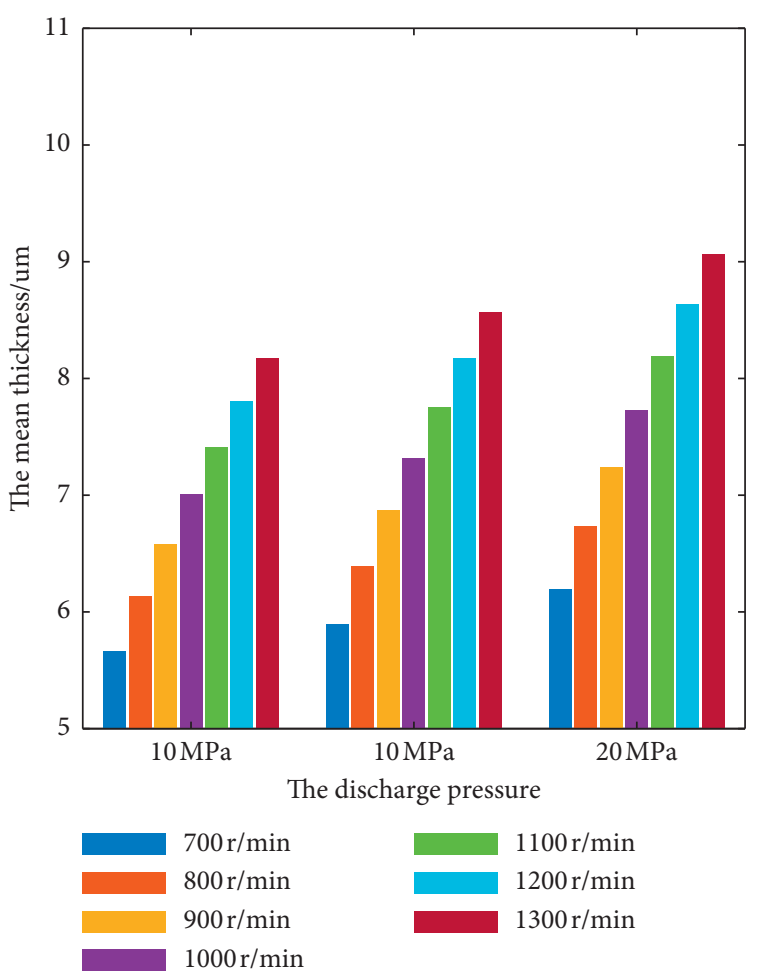

(a)
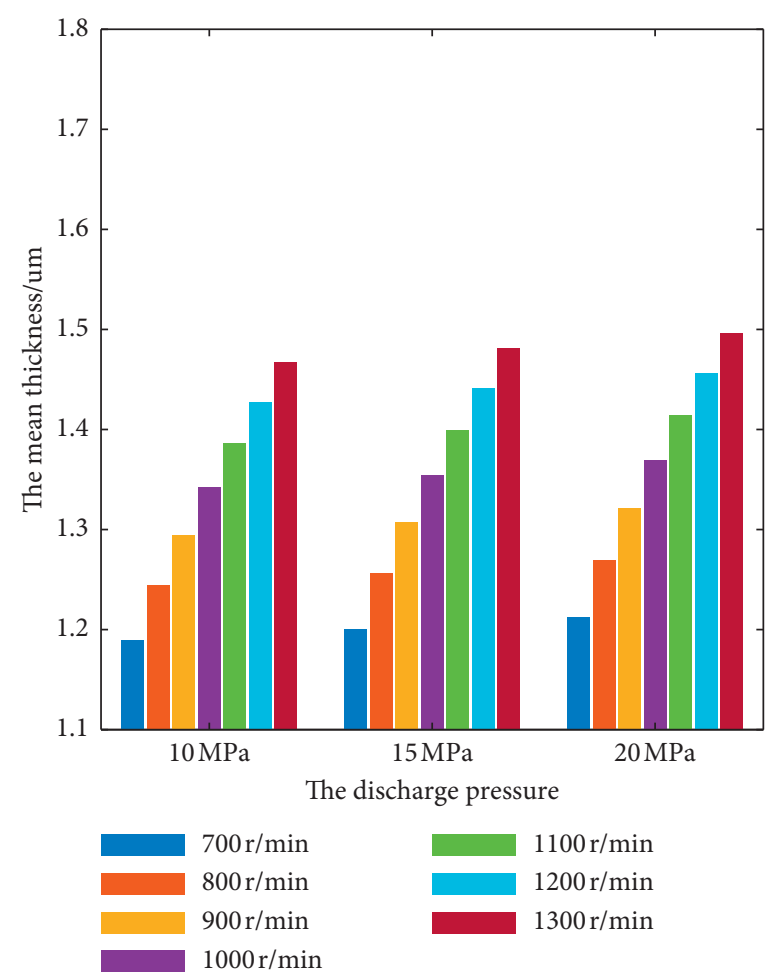

(b)

Figure 10: The mean value of the minimum thickness. (a) The discharge region; (b) the suction region.

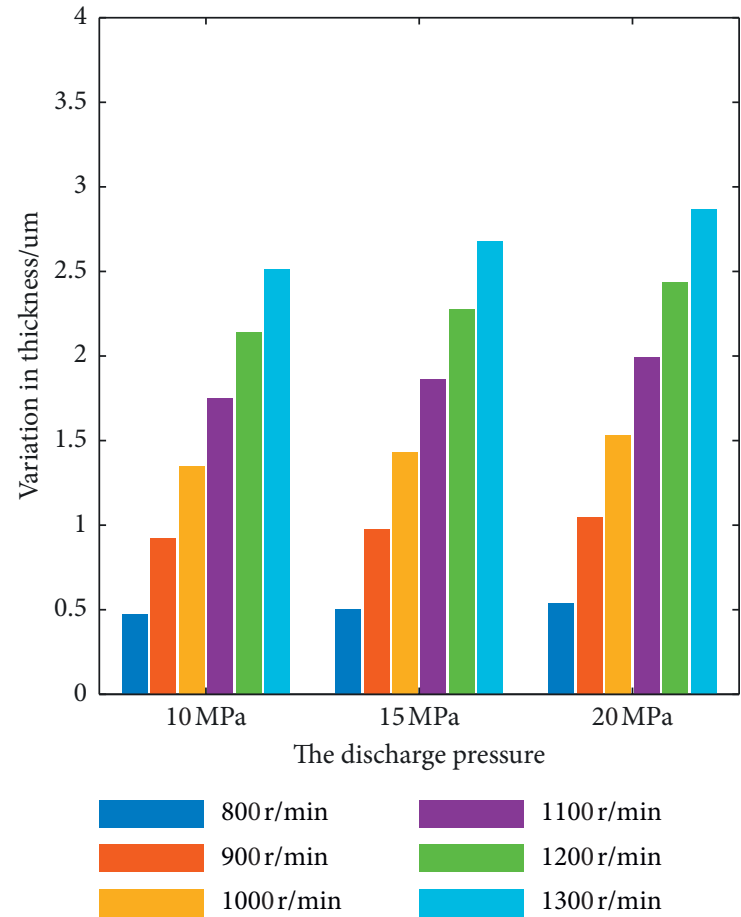

(a)

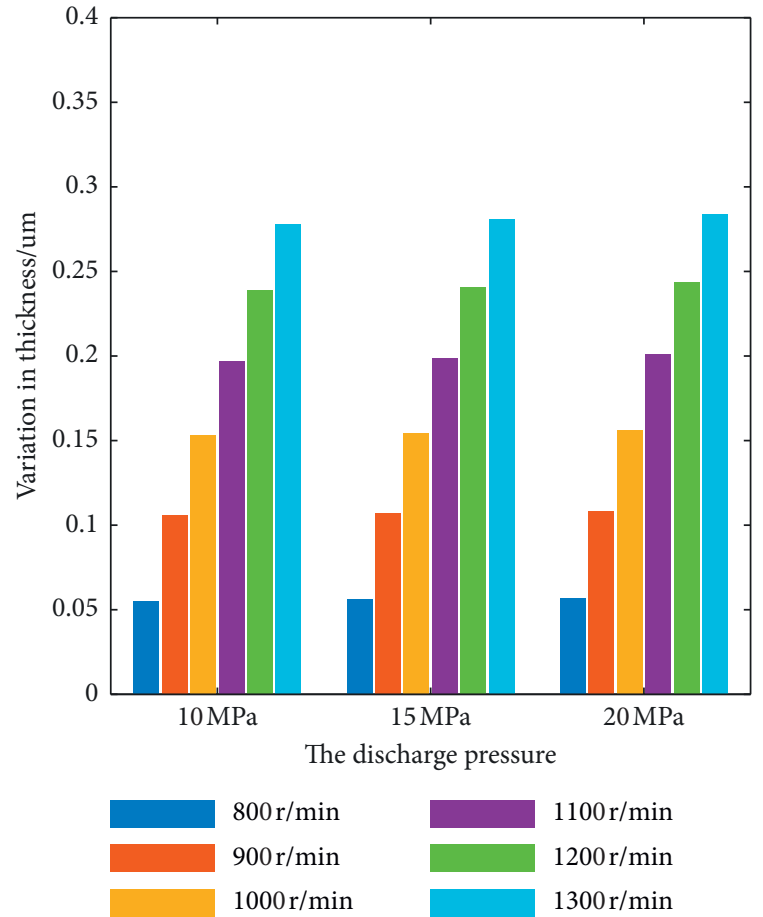

(b)

FIgURE 11: The variation of mean minimum film thickness. (a) The discharge region; (b) the suction region. 


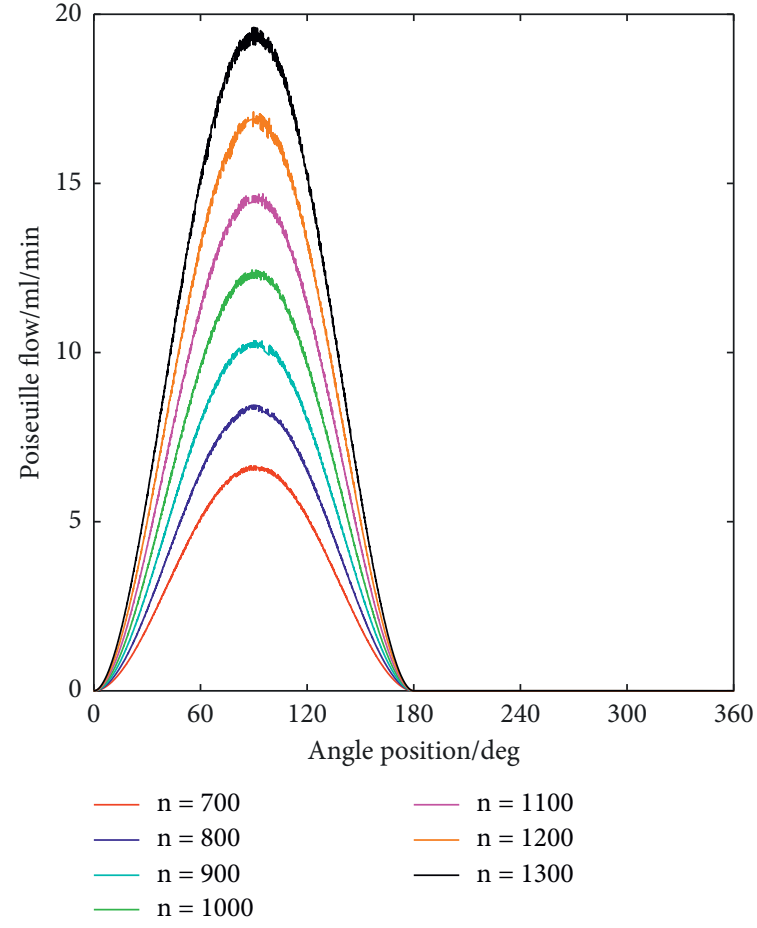

(a)

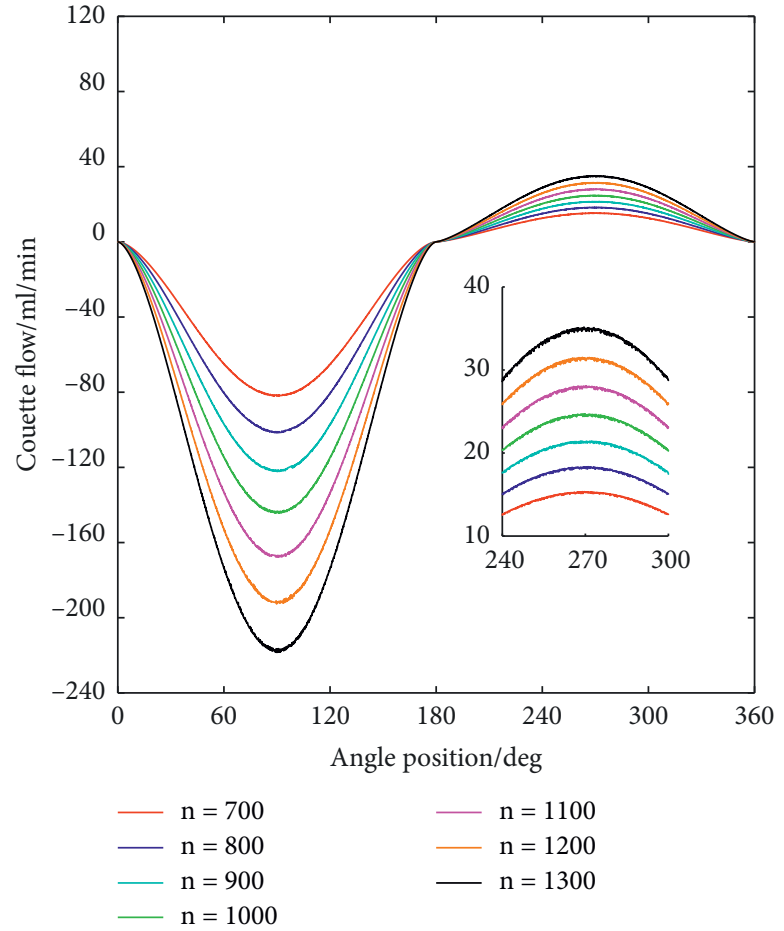

(b)

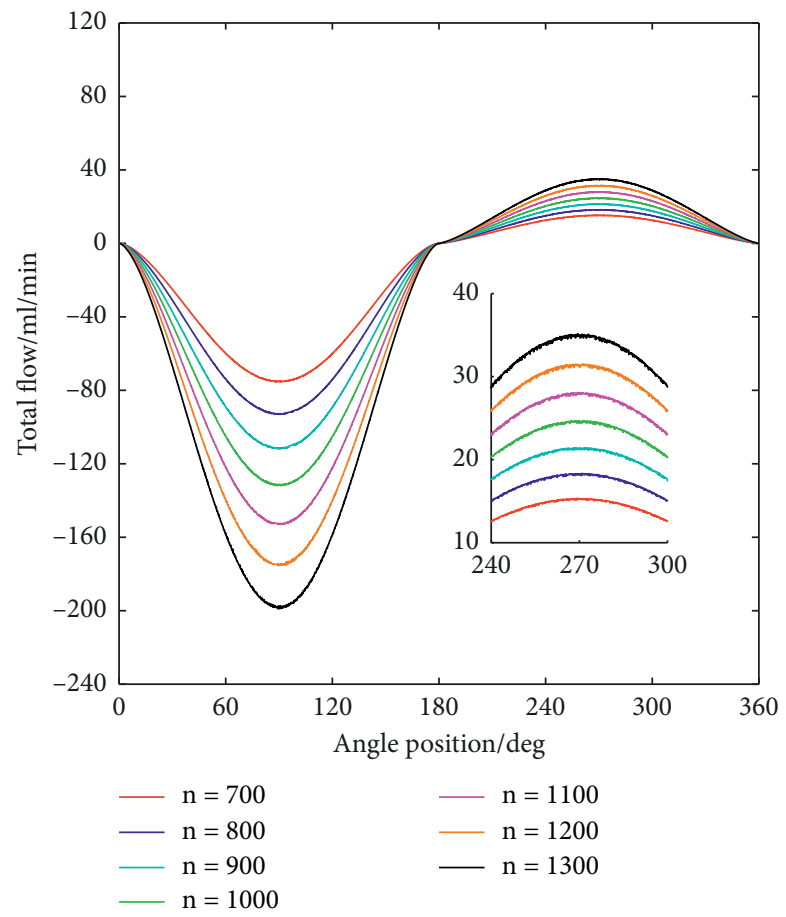

(c)

Figure 12: The leakage of PRCB per piston at different rotational speeds. (a) The Poiseuille flow; (b) the Couette flow; (c) the total flow rate.

increase of rotation speed, but the value in the discharge area is obviously larger than that in the suction region as shown in Figure 12(c).

The effect of the discharge pressure on the instantaneous flow rate of PRCB per piston is shown in Figure 13.
As shown in Figure 13, the Poiseuille flow first increases and then decreases with the increase of angular position in the discharge region and increases with the increase of speed as a whole, as shown in Figure 13(a). The Couette flow is negative in the discharge pressure region and is positive in 


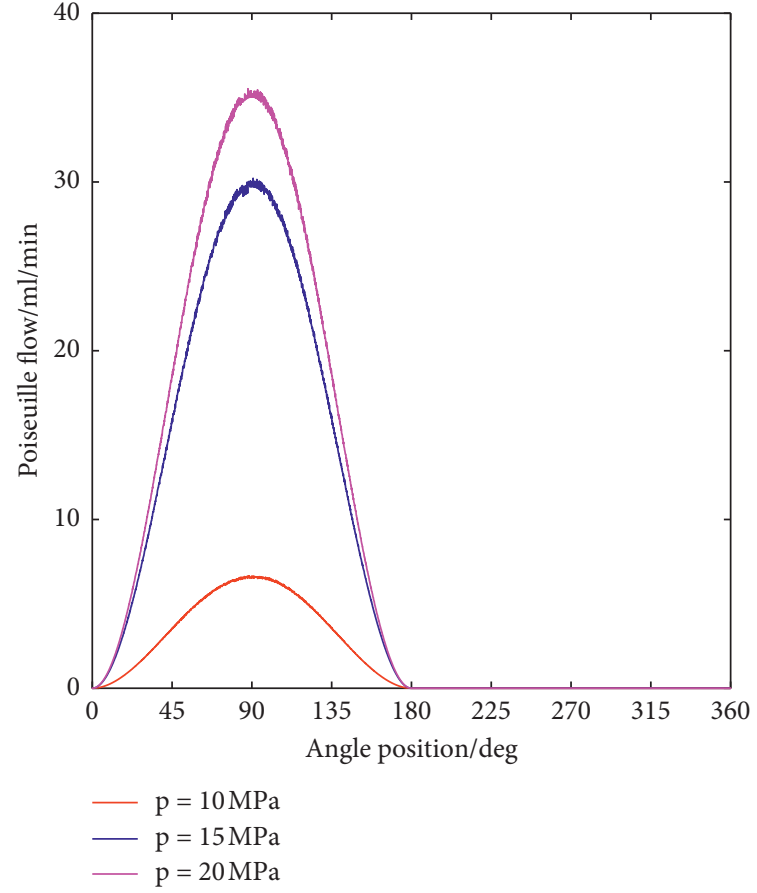

(a)

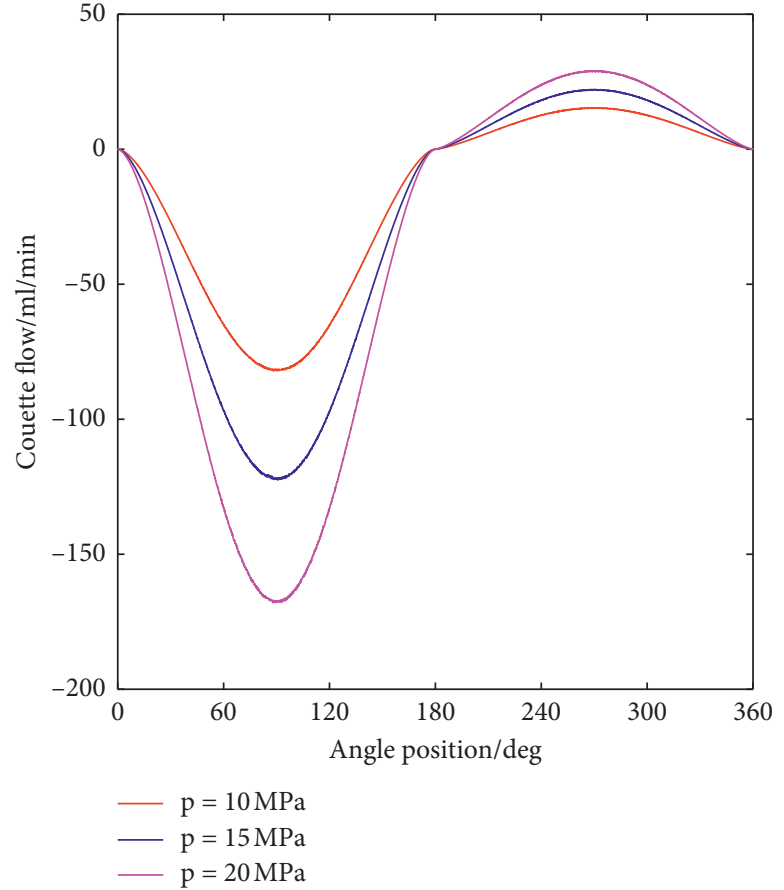

(b)

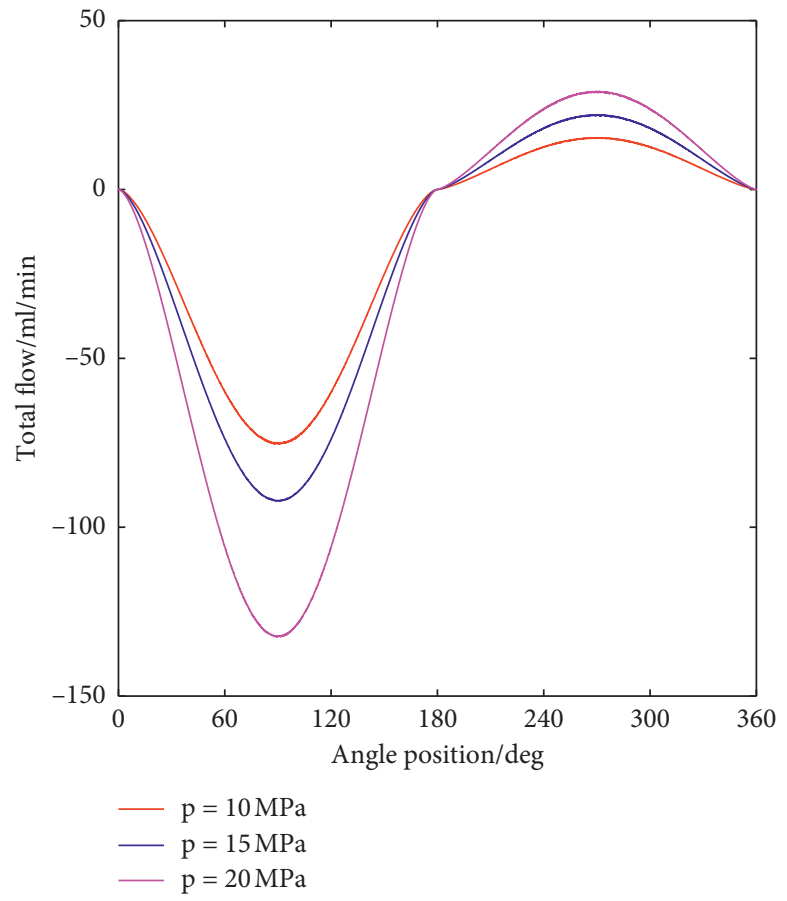

(c)

Figure 13: The leakage flow of PRCB per piston at different discharge pressures. (a) The Poiseuille flow; (b) the Couette flow; (c) the total flow rate.

the suction region. The value of the Couette flow first increases and then decreases with the increase of angular position, but the value of the Couette flow in the discharge region is significantly larger. When the speed increases from $700 \mathrm{r} / \mathrm{min}$ to $1300 \mathrm{r} / \mathrm{min}$, the leakage flow in the discharge region and suction region increases, but the variation of the former is larger, as shown in Figure 13(b). The total flow rate is negative in the discharge region and is positive in the suction region. The total flow rate increases with the increase of the speed and the discharge pressure, but the value in the discharge region is obviously larger than that in the suction region, as shown in Figure 13(c). 
The reason is that the Poiseuille flow is determined by the minimum thickness and the pressure difference between the displacement chamber and the pump case. The pressure difference and the minimum thickness increase with the increase of discharge pressure. Once the discharge pressure is determined, the pressure difference will basically remain unchanged. Therefore, the change trend of the Poiseuille flow consistent with the change trend of the minimum thickness in the discharge region under different the discharge pressure. The Couette flow is determined by the velocity of the piston ring and the minimum thickness between the piston ring and the cylinder, and the positive and negative of the Couette flow are determined by the direction of piston velocity. The leakage flow is caused by the Poiseuille flow and the Couette flow, and the two flows oppose in the discharge pressure region and support each other depending on in the suction region. According to Figures 12 and 13, the Couette flow plays a leading role in leakage flow of PRBC, especially the Couette flow in the discharge region.

The average leakage flow rate of PRCB per piston at different speeds is shown in Figure 14.

As shown in Figure 14, it is found that the average leakage flow is negative, which indicates the flow rate flows from the pump case to the displacement chamber. When the speed is constant, the average leakage flow rate increases with the increase of the discharge pressure. When the discharge pressure is constant, the average leakage flow rate increases with the increase of the speed. If the discharge pressure is $20 \mathrm{MPa}$, the mean increased from $27.9 \mathrm{ml} / \mathrm{min}$ to $75.6 \mathrm{ml} / \mathrm{min}$ with the increase of the speed from $700 \mathrm{r} / \mathrm{min}$ to $1300 \mathrm{r} / \mathrm{min}$, which increased by 171 percent.

\section{Experimental Results}

4.1. Test Rig Description. The leakage flow rate of PRCB is difficult to measure directly. According to the previous works $[21,23]$, the leakage flow rate of PRCB is an important part of the return oil flow rate. Therefore, the return oil flow rate is measured to investigate the effects of rotation speed on the leakage flow of PRCB. The bent-axis piston pump experiments are implemented on a test rig, as shown in Figure 15.

As shown in Figure 15, the test rig consists of a bent-axis piston pump, a motor, a speed sensor, a pressure senor, a temperature senor, and a relief valve and so on. The bentaxis piston pump is continuously adjusted from 0 to $2000 \mathrm{r} /$ min by the motor. The return oil flow rate is measured by the flow sensor which is installed on the outlet of the pump case in the bent-axis piston pump. The discharge pressure is controlled by adjusting the relief valve. The signals obtained from the main sensors are collected using NI acquisition card and LabVIEW software. The detailed descriptions of the main parameters of the test rig are shown in Table 2.

4.2. Data Processing. The data acquisition diagram of return oil flow rate in the bent-axis piston pump is presented in Figure 16. The sampling frequency was $1 \mathrm{~Hz}$, and the time

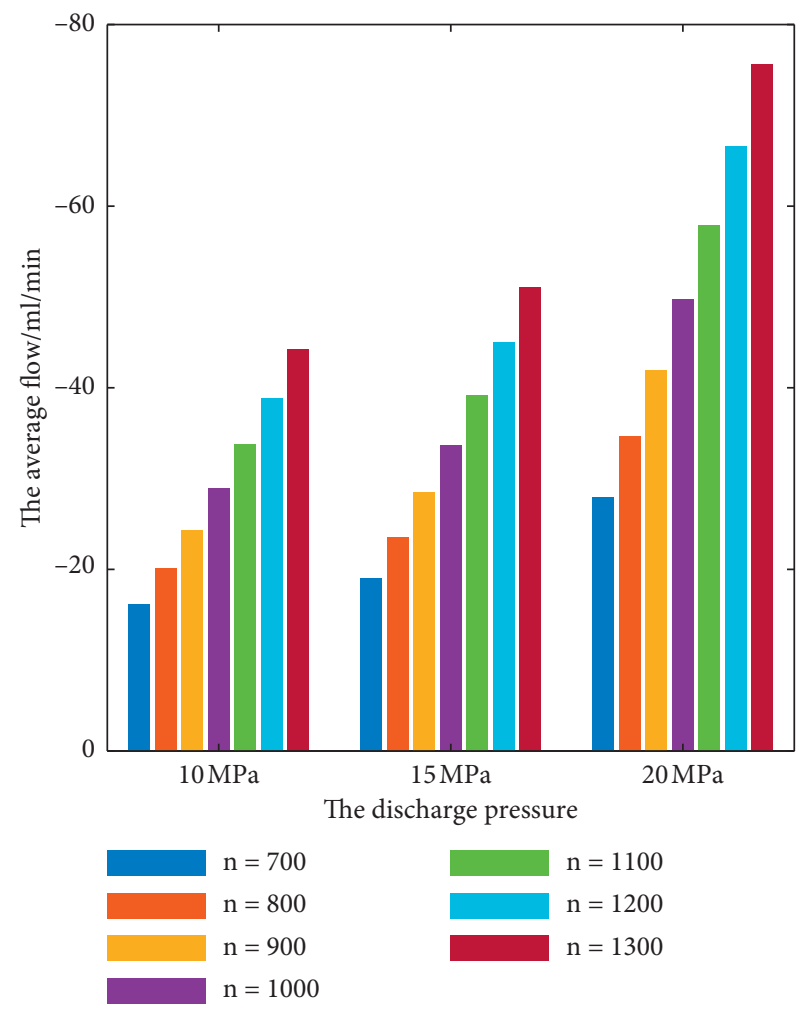

FIgURE 14: The average leakage flow of PRBC per piston at different speeds.

interval was $35 \mathrm{~s}$ under different working conditions. The empirical mode decomposition (EMD) was used to deal with the return oil flow rate under $p=20 \mathrm{MPa} n=1300 \mathrm{r} / \mathrm{min}$ to obtain its intrinsic mode functions (IMF), as shown in Figure 16(a). According to the noise reduction and smoothing of the collected the return oil flow rate data, the return oil flow rate diagram under different working conditions is shown in Figure 16(b). It can be seen from this figure that the overall trend of the return oil flow rate decreases with the increase of rotation speed.

4.3. Results Analysis. The simulated flow rate of PRCB and the measured the return oil flow rate in the bent-axis piston pump is shown in Figure 17.

In Figure 17, it is obvious that the simulated total flow rate of $\mathrm{PRCB}$ is negative, and its value increases with the increase of speed and discharge pressure, but the measured the return oil flow rate decreases with the increase of speed and increases with the increase of discharge pressure. The reason is that the measured the return oil flow rate is composed of the leakage of VPCB and the leakage of PRCB. The leakage of VPCB is the main part of the measured the return oil flow rate, and its values increases with the increase of the discharge pressure and is less affected by rotation speed. But the flow rate of PRCB is negative, which leads to the decrease of the measured return oil flow rate.

The variations of the simulated flow of PRCB and the measured return flow rate relative to the flow rate under the same discharge pressure and $700 \mathrm{r} / \mathrm{min}$ is shown in Figure 18. 


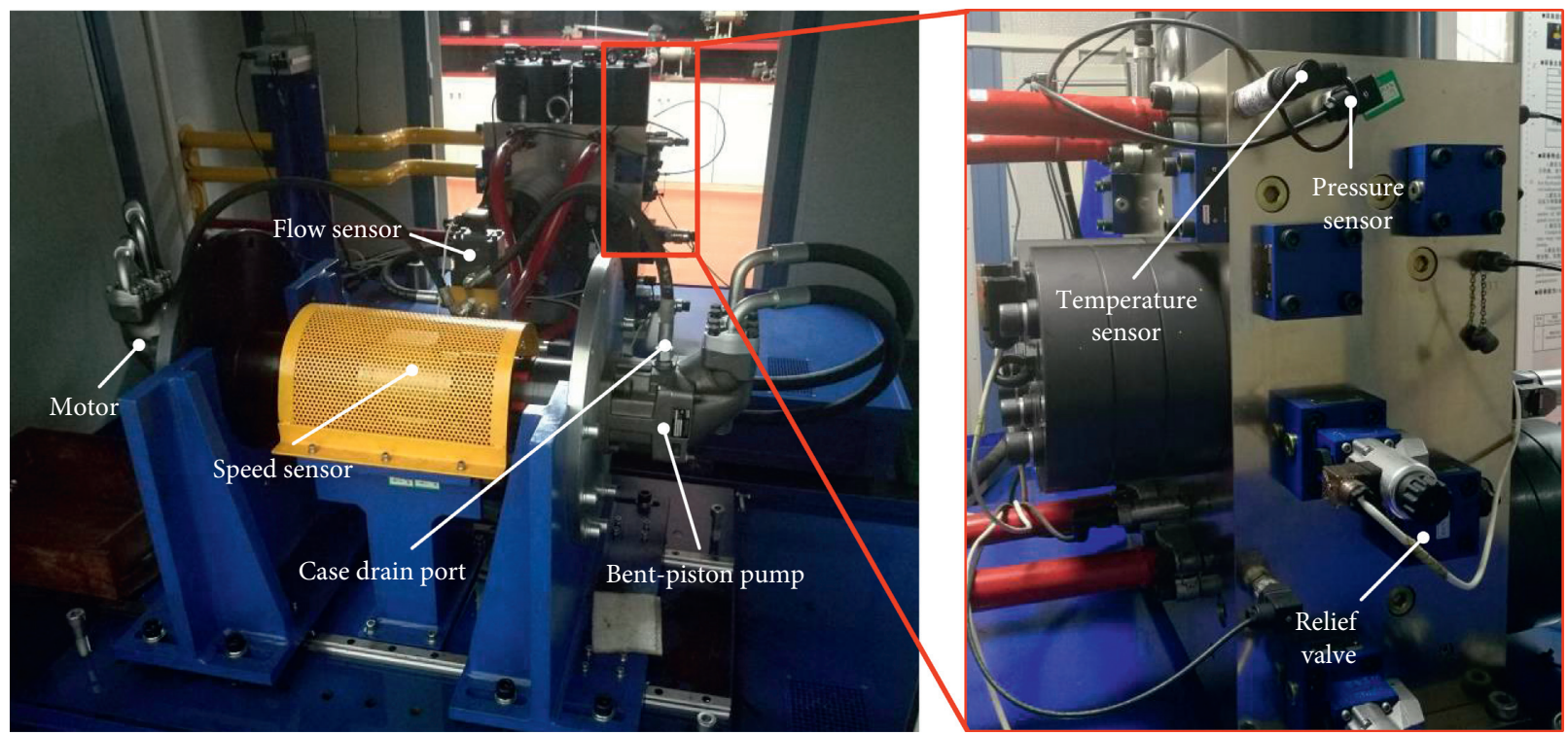

Figure 15: Photograph of the test rig.

TABLE 2: The main parameters of the test rig.

Devices Descriptions

The bent-axis piston Displacement: $80.4 \mathrm{ml} / r$; operating pressure: 0-42 MPa; max self-priming speed: $2300 \mathrm{r} / \mathrm{min}$ flow sensor: $0.02-41 /$ pump min, $\pm 0.3 \%$; pressure sensor: $0-60 \mathrm{MPa}, \pm 0.05 \%$

The main sensors Speed sensor: $0-6000 \mathrm{r} / \mathrm{min}, \pm 1 \mathrm{rpm}$; temperature sensor: $-25-100^{\circ} \mathrm{C}, \pm 0.8 \%$
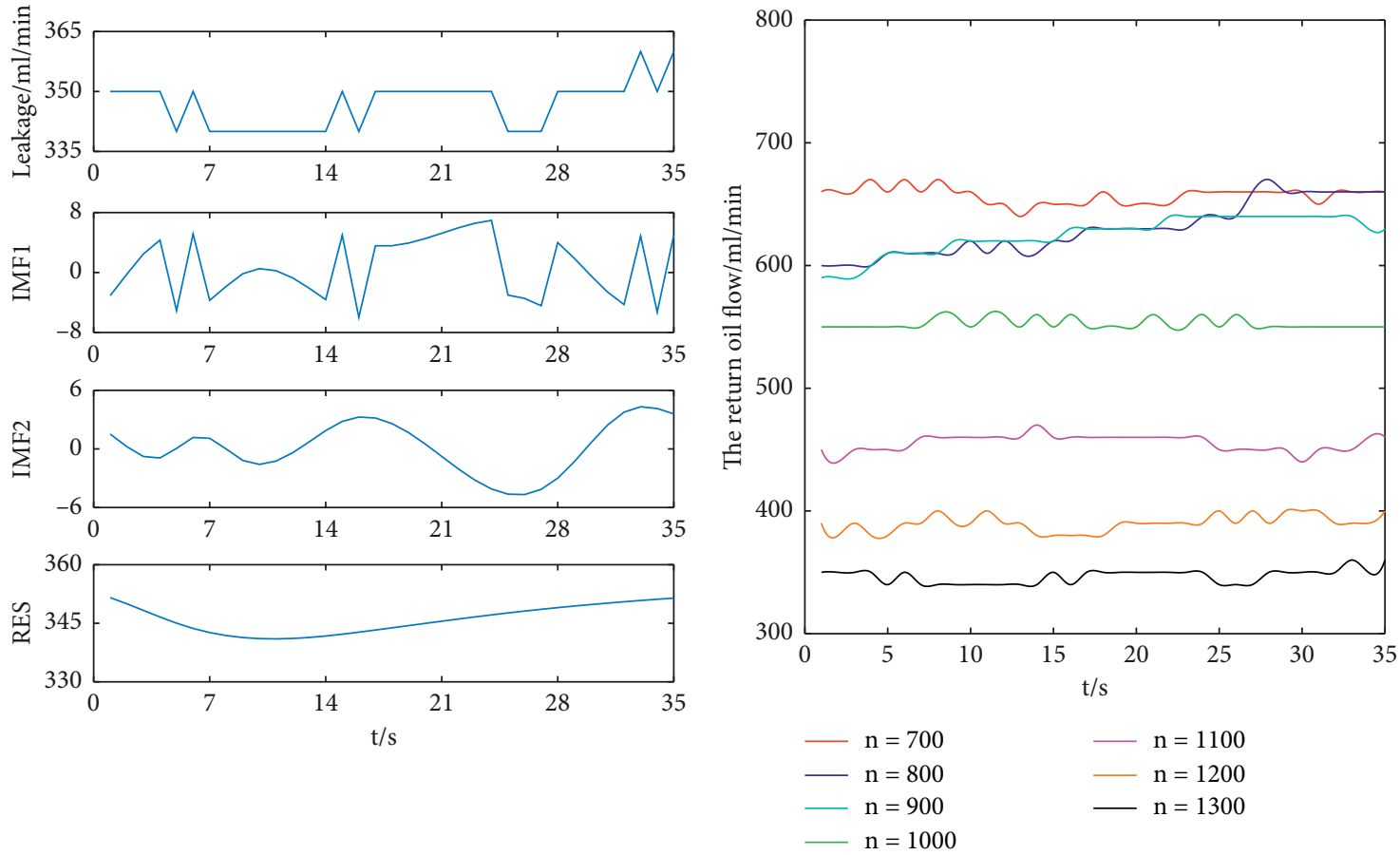

(a)

(b)

FIgURE 16: The data acquisition diagram of the return oil flow rate. (a) The return oil flow rate data EMD results under $p=20 \mathrm{MPa} n=1300$ $\mathrm{r} / \mathrm{min}$; (b) the return oil flow rate under different working conditions. 


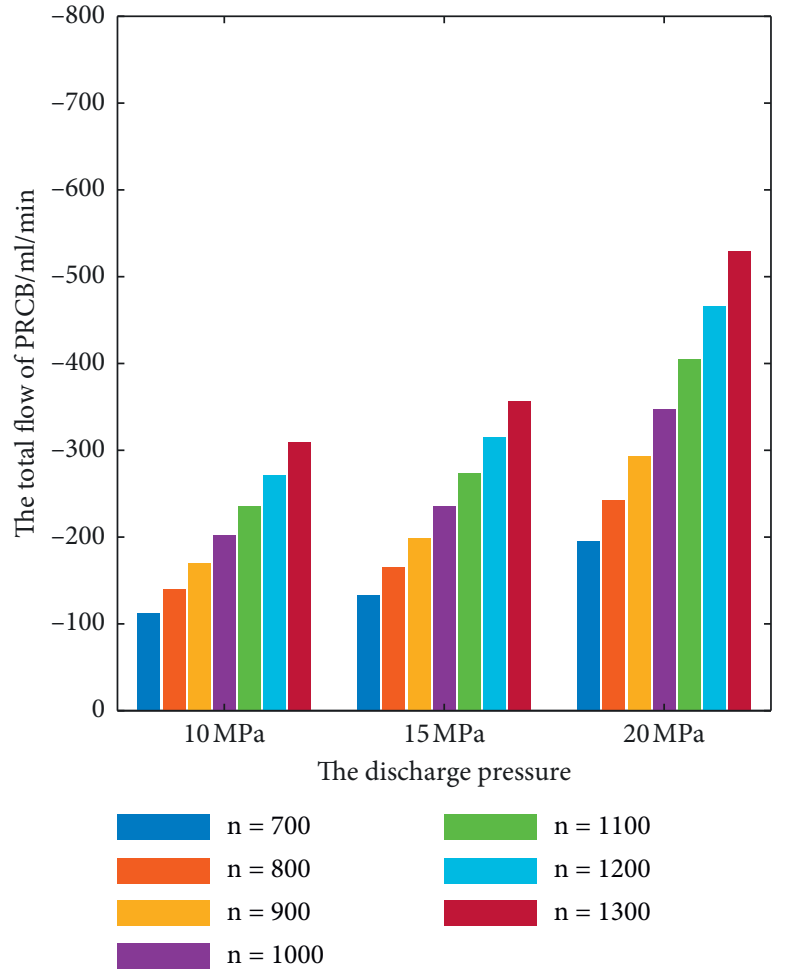

(a)

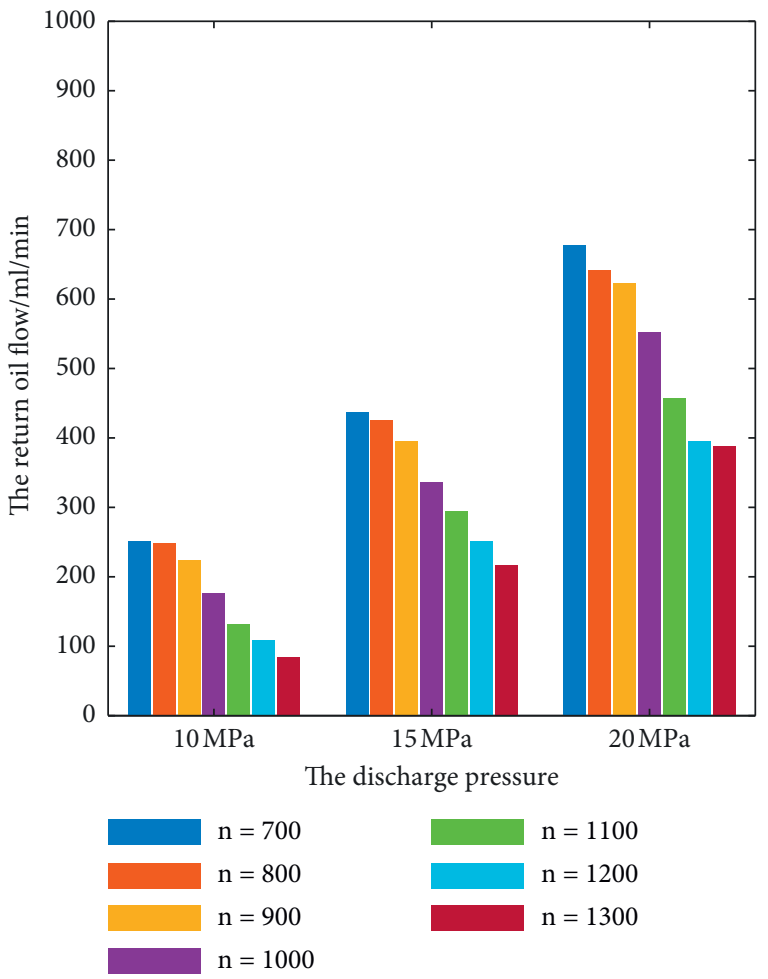

(b)

FIGURE 17: Simulated results and measured results. (a) Simulating the total flow rate of PRCB; (b) measuring the return oil flow rate.

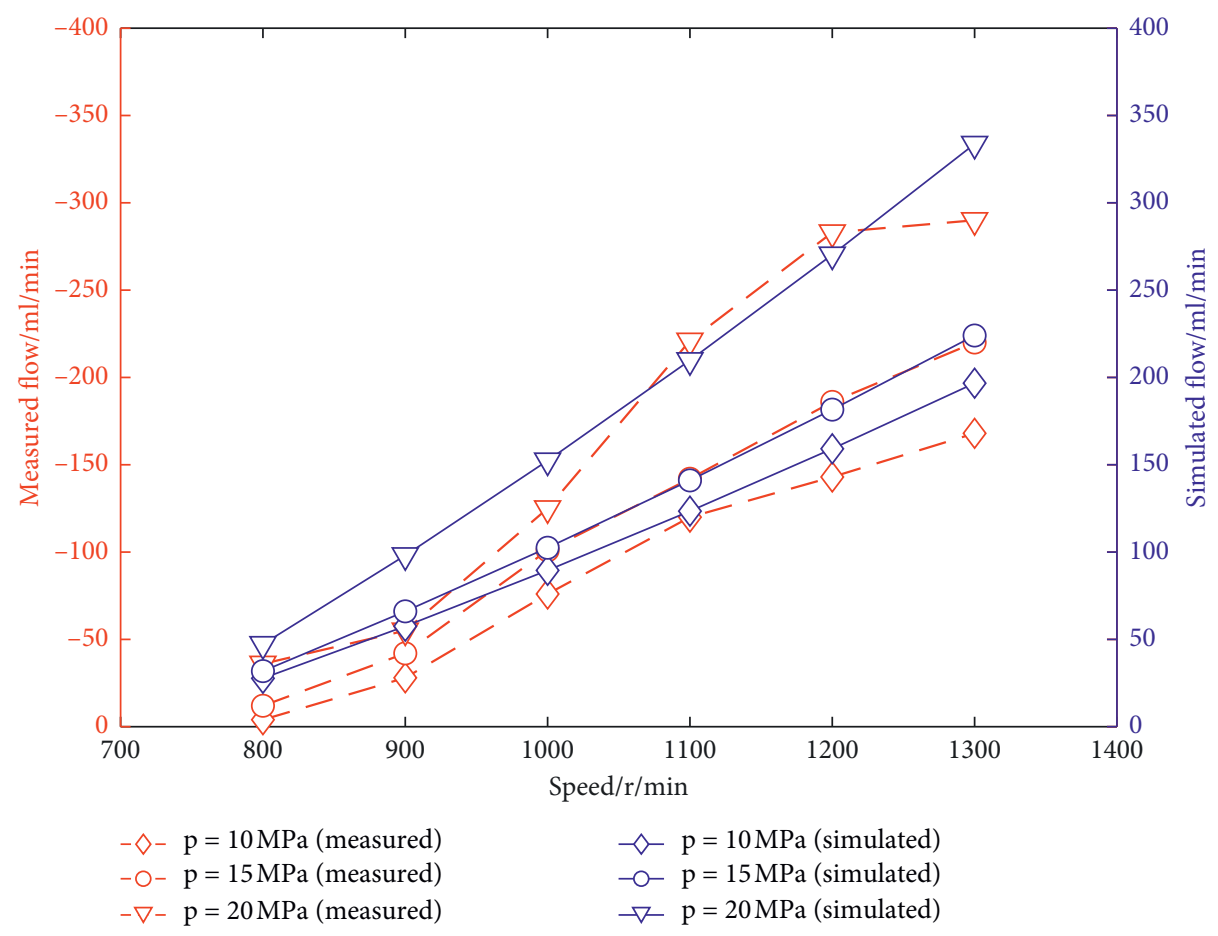

FIGURE 18: The variations of the simulated flow of PRCB and the measured return flow rate.

In this picture, it is obvious that the variations of the simulated flow of PRCB increase with the increase of rotation speed, indicating that the simulated flow of PRCB increases with the increase of speed. The variation of the measured return flow rate is negative, and it decreases with the increase of rotation speed, indicating that the measured 
return flow rate decreases with the increase of rotation speed. Moreover, the trend of the two variations with rotation speed is basically the same at the different discharge pressure. However, there is a certain difference between the two; its maximum is $44 \mathrm{ml} / \mathrm{min}$ at $n=1300 \mathrm{r} / \mathrm{min}$ and $p=20 \mathrm{MPa}$. The main reason is that the measured result is by the leakage flow of PRCB but also by the leakage flow of VPCB.

\section{Conclusions}

The model is suitable for analyzing the dynamic change of the minimum oil film of PRCB under the action of elastohydrodynamic lubrication. Combining the minimum oil film model with the flow equation, a mathematical model of PRCB is introduced to help produce the effect of the oil film on the leakage of PRCB. The effect of rotation speed on the leakage flow of PRCB is analyzed through simulation and experiment, and the following conclusions are obtained.

(1) The lubrication of PRCB in the discharge of oil segment belongs to the elastohydrodynamic lubrication, and the angle position of the maximum oil film pressure is close to the top dead point $0^{\circ}$ with the increase of rotation speed, but its maximum pressure value is basically not affected by the change of the rotation speed.

(2) The minimum thickness of PRCB increases with the increase of rotation speed, and its value in the discharge of oil segment is greater than that in the suction of oil segment, and the former varies more with the rotation speed.

(3) The average flow rate of PRCB is from the pump case to the displacement chamber, which reduces the return oil flow rate in the pump case. The return oil flow rate decreases with the increase of rotation speed, and the effect of rotation speed on the average flow rate of PRCB and the return oil flow rate is also remarkable under the high discharge pressure.

The return oil flow rate in the bent-axis piston pump should be the synthesis of the two friction pairs, which are related to the rotation speed. In this paper, the relationship between the elastohydrodynamic lubrication characteristics of PRCB and the rotation speed is analyzed. The relationship between leakage of the valve plate-cylinder block interface and rotation speed in the bent-axis piston pump will be the focus of further work.

\section{Data Availability}

The data that support the findings of this study are available on request from the corresponding author. These data were derived from the test rig built by the authors.

\section{Conflicts of Interest}

The authors declare that they have no conflicts of interest.

\section{Acknowledgments}

This research was funded by the National Natural Science Foundation of China (no. 51675399), Special Research Project of Education Department of Shaanxi Province (no. 18JK0408), and the Science Foundation of Xi'an Aeronautical University (no. 2020KY0223).

\section{References}

[1] S. Cun, W. Shaoping, W. Xingjian, and Y. Zhang, "Variable load failure mechanism for high-speed load sensing electrohydrostatic actuator pump of aircraft," Chinese Journal of Aeronautics, vol. 31, pp. 949-964, 2018.

[2] J. Du, S. Wang, L. Han, S. Zhao, and C. Guo, "Prognostic management verification system of aircraft hydraulic power supply system," in Proceedings of 10th IEEE International Conference on Industrial Informatics (INDIN), Beijing, China, July 2012.

[3] Y. Hong and Y. Doh, "Analysis on the friction losses of a bentAxis type hydraulic piston pump," Journal of Mechanical Science and Technology, vol. 18, pp. 1668-1679, 2004.

[4] K. Feng, P. Borghesani, W. A. Smith et al., "Vibration-based updating of wear prediction for spur gears," Wear, vol. 426427, pp. 1410-1415, 2019.

[5] F. Zhao, Z. Tian, X. Liang, and M. Xie, "An integrated prognostics method for failure time prediction of gears subject to the surface wear failure mode," IEEE Transactions on Reliability, vol. 67, no. 1, pp. 316-327, 2018.

[6] B. Sun, Y. Li, Z. Wang, Y. Ren, Q. Feng, and D. Yang, "An Improved Inverse Gaussian Process with Random Effects and Measurement Errors for RUL Prediction of Hydraulic Piston Pump," Measurement, vol. 173, Article ID 108604, 2020.

[7] F. Lyu, J. Zhang, G. Sun et al., "Research on wear prediction of piston/cylinder pair in axial piston pumps," Wear, vol. 456457, pp. 203338-203410, 2020.

[8] Z. Ma, S. Wang, J. Shi, T. Li, and X. Wang, "Fault diagnosis of an intelligent hydraulic pump based on a nonlinear unknown input observer," Chinese Journal of Aeronautics, vol. 31, no. 2, pp. 385-394, 2018.

[9] J. Ma, J. Chen, J. Li, Q. Li, and C. Ren, "Wear analysis of swash plate/slipper pair of axis piston hydraulic pump," Tribology International, vol. 90, pp. 467-472, 2015.

[10] N. Kumar, B. K. Sarkar, and S. Maity, "Leakage based condition monitoring and pressure control of the swashplate Axial piston pump," in Proceedings of ASME 2019 Gas Turbine India Conference, Chennai, Tamil Nadu, India, 2019.

[11] D. Bensaad, A. Soualhi, and F. Guillet, "A new leaky piston identification method in an axial piston pump based on the extended Kalman filter," Measurement, vol. 148, Article ID 106921, 2019.

[12] Z. Ma, S. Wang, H. Liao, and C. Zhang, "Engineering-driven performance degradation analysis of hydraulic piston pump based on the inverse Gaussian process," Quality and Reliability Engineering International, vol. 35, pp. 2278-2296, 2019.

[13] R. Guo, Z. Zhao, S. Huo, Z. Jin, J. Zhao, and D. Gao, "Research on state recognition and failure prediction of axial piston pump based on performance degradation data," Processes, vol. 8, no. 5, p. 609, 2020.

[14] X. Wang, S. Lin, S. Wang, Z. He, and C. Zhang, "Remaining useful life prediction based on the Wiener process for an aviation axial piston pump," Chinese Journal of Aeronautics, vol. 29, no. 3, pp. 779-788, 2016. 
[15] M. Pelosi, An Investigation of the Fluid-Structure Interaction of Piston/cylinder Interface, Purdue University, West Lafayette, Indiana, 2012.

[16] Y. Song, J. Ma, and S. Zeng, "A numerical study on influence of temperature on lubricant film characteristics of the piston/ cylinder interface in axial piston pumps," Energies, vol. 11, no. 7, p. 1842, 2018.

[17] D. Qian and R. Liao, "A nonisothermal fluid-structure interaction analysis on the piston/cylinder interface leakage of high-pressure fuel pump," Journal of Tribology, vol. 136, 2014.

[18] J. Zhang, B. Liu, R. Lü, Q. Yang, and Q. Dai, "Study on oil film characteristics of piston-cylinder pair of ultra-high pressure axial piston pump," Processes, vol. 8, no. 1, p. 68, 2020.

[19] S. Nie, M. Guo, F. Yin et al., "Research on fluid-structure interaction for piston/cylinder tribopair of seawater hydraulic axial piston pump in deep-sea environment," Ocean Engineering, vol. 219, Article ID 108222, 2021.

[20] I. Cho, I. Beak, J. Jo, J. Park, S. Oh, and J. Jung, "Lubrication characteristics of dual piston ring in bent-axis type piston pumps," Journal of Mechanical Science and Technology, vol. 24, no. 6, pp. 1363-1368, 2010.

[21] R. Kumar, A Study of the Piston Ring - Cylinder Bore Interface for Bent axis Axial Piston Pump Using an Advanced Computer Model, ETD Collection for Purdue University, West Lafayette, Indiana, 2009.

[22] B. Manhartsgruber, "The dynamics of leakage in bent Axis units without timing gear," in Proceedings of BATH/ASME 2016 Symposium on Fluid Power and Motion Control, Bath, UK, October 2016.

[23] J. Zhang, Y. Li, D. Zhang, B. Xu, F. Lv, and Q. Chao, “A centrifugal force interaction analysis on the piston/cylinder interface leakage of bent-Axis type piston pumps," in Proceedings of 2016 Ieee/Csaa International Conference on Aircraft Utility Systems (Aus), Beijing, China, June 2016.

[24] J.-M. Liu, L.-C. Gu, and B.-L. Geng, "A practical signal processing approach for fault detection of axial piston pumps using instantaneous angular speed," Proceedings of the Institution of Mechanical Engineers, Part C: Journal of Mechanical Engineering Science, vol. 234, no. 19, pp. 3935-3947, 2020.

[25] L. Gu, Q. Tian, and Z. Ma, "Extraction of the instantaneous speed fluctuation based on normal time-frequency transform for hydraulic system," Proceedings of the Institution of $\mathrm{Me}$ chanical Engineers, Part C: Journal of Mechanical Engineering Science, vol. 234, no. 6, pp. 1196-1211, 2020.

[26] L. Gu, R. Xu, and N. Wang, "A novel reduced order dynamic model of axial piston motors with compression flow losses and Coulomb friction losses," Industrial Lubrication and Tribology, vol. 72, no. 5, pp. 567-573, 2019.

[27] Y. Liu, L. C. Gu, B. Yang, S. H. Wang, and H. B. Yuan, “A new evaluation method on hydraulic system using the instantaneous speed fluctuation of hydraulic motor," Proceedings of the Institution of Mechanical Engineers Part C Journal of Mechanical Engineering Science, vol. 232, no. 15, pp. 26742684, Article ID 095440621772257, 2018.

[28] B. J. Hamrock and B. O. Jacobson, "Elastohydrodynamic lubrication of line contacts," A S L E Transactions, vol. 27, no. 4, pp. 275-287, 1984.

[29] J. Pei, X. Han, and Y. Tao, “An Improved Stiffness Model for Line Contact Elastohydrodynamic Lubrication and its Application in Gear Pairs," Industrial Lubrication and Tribology, vol. 72, no. 5, pp. 703-708, 2020.

[30] Y. Zhang, H. Liu, C. Zhu, C. Song, and Z. Li, "Influence of lubrication starvation and surface waviness on the oil film stiffness of elastohydrodynamic lubrication line contact," Journal of Vibration and Control, vol. 24, no. 5, pp. 924-936, 2018.

[31] N. A. H. Tsuha and K. L. Cavalca, "Finite line contact stiffness under elastohydrodynamic lubrication considering linear and nonlinear force models," Tribology International, vol. 146, Article ID 106219, 2020. 